Article

\title{
Impact of Outdoor Air Pollution on Indoor Air Quality in Low-Income Homes during Wildfire Seasons
}

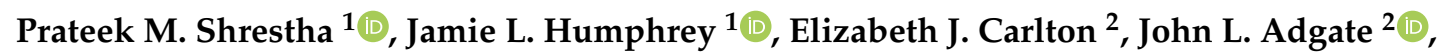 \\ Kelsey E. Barton ${ }^{2}$, Elisabeth D. Root $^{3}$ and Shelly L. Miller 1,*(D) \\ 1 Department of Mechanical Engineering, University of Colorado Boulder, Boulder, CO 80309, USA; \\ prateek.shrestha@colorado.edu (P.M.S.); jlh563@drexel.edu (J.L.H.) \\ 2 Department of Environmental and Occupational Health, University of Colorado, Colorado School of Public \\ Health, Aurora, CO 80045, USA; ELIZABETH.CARLTON@ucdenver.edu (E.J.C.); \\ john.adgate@ucdenver.edu (J.L.A.); KELSEY.BARTON@ucdenver.edu (K.E.B.) \\ 3 Department of Geography and Division of Epidemiology, The Ohio State University, 1036 Derby Hall, \\ 154 North Oval Mall, Columbus, OH 43210, USA; root.145@osu.edu \\ * Correspondence: shelly.miller@colorado.edu; Tel.: +1-303-492-0587
}

Received: 4 August 2019; Accepted: 18 September 2019; Published: 21 September 2019

\begin{abstract}
Indoor and outdoor number concentrations of fine particulate matter $\left(\mathrm{PM}_{2.5}\right)$, black carbon $(\mathrm{BC})$, carbon monoxide $(\mathrm{CO})$, and nitrogen dioxide $\left(\mathrm{NO}_{2}\right)$ were monitored continuously for two to seven days in 28 low-income homes in Denver, Colorado, during the 2016 and 2017 wildfire seasons. In the absence of indoor sources, all outdoor pollutant concentrations were higher than indoors except for $\mathrm{CO}$. Results showed that long-range wildfire plumes elevated median indoor $\mathrm{PM}_{2.5}$ concentrations by up to 4.6 times higher than outdoors. $\mathrm{BC}, \mathrm{CO}$, and $\mathrm{NO}_{2}$ mass concentrations were higher indoors in homes closer to roadways compared to those further away. Four of the homes with mechanical ventilation systems had $18 \%$ higher indoor/outdoor $(\mathrm{I} / \mathrm{O})$ ratios of $\mathrm{PM}_{2.5}$ and $4 \%$ higher $\mathrm{I} / \mathrm{O}$ ratios of BC compared to other homes. Homes with exhaust stove hoods had $\mathrm{PM}_{2.5} \mathrm{I} / \mathrm{O}$ ratios $49 \%$ less than the homes with recirculating hoods and 55\% less than the homes with no stove hoods installed. Homes with windows open for more than 12 hours a day during sampling had indoor BC 2.4 times higher than homes with windows closed. This study provides evidence that long-range wildfire plumes, road proximity, and occupant behavior have a combined effect on indoor air quality in low-income homes.
\end{abstract}

Keywords: low-cost sensors; black carbon; $\mathrm{PM}_{2.5}$; infiltration; energy efficiency; traffic-related air pollution; wildfire smoke

\section{Introduction}

Homes are meant to keep us safe against undesirable natural elements including outdoor air pollution. We spend the majority of our time indoors and often at home, and thus exposure to air pollution in our homes is an ongoing concern [1]. Indoor air quality is degraded by air pollutants of both indoor and outdoor origins. In addition to indoor emissions from activities like cooking and cleaning, a major source of air pollution in homes is the infiltration of outdoor air pollutants. Infiltration refers to the transport of air due to pressure and temperature differences in and out of homes through unintentional openings. Outdoor air pollution can also come indoors through open windows and doors or by supply air ventilation systems. Every year, as climate change continues to impact our environment in addition to rapid population growth and increased anthropogenic emissions, outdoor air quality impacts include increases in summertime ozone in urban areas, particulate matter due to 
more frequent wildfires, and airborne pollens, molds and biogenic volatile organic compounds [2-5], making exposure to outdoor air pollution more and more extreme and resulting in higher health risks, especially in the sensitive receptors of urban areas. Indoor environments of homes are the most obvious first line of defense against these air pollutants. In this study, we continuously monitored indoor and outdoor air pollutants in 28 low-income homes to study the impacts of outdoor air pollutants on indoor air quality during wildfire seasons.

The highest levels of outdoor air pollution in the Denver metro area of Colorado can be expected during the summer season (the months of June through October of every year) [6]. During this time of the year, outdoor particulate matter levels are elevated due to the usual background level of traffic-related emissions superimposed with atmospheric chemistry processes [7-9] and aerosols produced by both short- and long-range wildfires, which are increasing in number over the decades as a result of climate change $[10,11]$. Studies have shown that wildfire smoke can be transported by wind and can affect the air quality, visibility, and atmospheric chemistry of places that are hundreds of kilometers away from the locations of wildfires [12-15]. The plumes from wildfires that occur annually during this time in the western United States and Canada can significantly affect the Denver metro area of Colorado.

Infiltration rates of outdoor fine particulate matter in the size range of 2.5 microns $\left(\mathrm{PM}_{2.5}\right)$, like those emitted from wildfires, are known to be higher in homes compared to the coarse and ultrafine particulate matter size ranges [16-18]. Wildfire smoke-related $\mathrm{PM}_{2.5}$ can take a few minutes to a few hours to infiltrate indoors but can persist for up to eight to ten hours [19]. Outdoor $\mathrm{PM}_{2.5}$ can infiltrate indoors in buildings even with closed windows and merely staying indoors provides limited protection against outdoor PM [20]. Many past studies have concluded that wildfire $\mathrm{PM}_{2.5}$ are important sources of adverse respiratory health outcomes [21-23] and staying indoors combined with the use of air cleaners can effectively reduce $\mathrm{PM}_{2.5}$ exposure during wildfire seasons [19,24-26]. In many communities, the use of air cleaning technology is often overlooked due to cost and a lack of information.

In addition to the worsening of outdoor air by wildfire plumes, people living in urban homes situated near a major road or a highway are exposed to significantly higher levels of traffic-related air pollutants like black carbon (BC), carbon monoxide (CO), and nitrogen dioxide $\left(\mathrm{NO}_{2}\right)$-all of which have been associated with adverse health effects including the increased risk of cardiovascular diseases, stroke, and reduced life expectancy [27-29]. $\mathrm{NO}_{2}$ is a known respiratory tract irritant and marker for traffic-related air pollution [30]. Results from our Colorado Home Energy Efficiency and Respiratory Health (CHEER) study showed that residents living in low-income single-family homes near major roads report more adverse respiratory symptoms compared to residents who live farther than $200 \mathrm{~m}$ away [31].

People living in the same geographic location are similarly affected by outdoor air pollution. However, low-income populations are often more vulnerable to the effects of climate change and outdoor air pollution due to financial constraints which compromise their ability to mitigate or adapt to changing environmental conditions which impact health [32-34]. Many low-income communities are also disproportionally located in areas with poor environmental conditions and close to high-traffic roads [35-37], leading to the unequal burden of potential health impacts. Low-income communities are therefore an important, and underrepresented, community to consider. However, there are limited data related to the indoor air quality in low-income homes, which this study aimed to fulfill.

The key objectives of this study were to better understand how the indoor air quality of low-income homes is impacted by (1) outdoor air pollutants during wildfire seasons when they can be expected to be at their maximum levels, and (2) what role certain characteristics of homes and occupant behavior play to worsen or mitigate those impacts.

\section{Materials and Methods}

This section describes the various materials and methods used in the study. 


\subsection{Study Recruitment}

Households located in Denver and the northern front range of Colorado were recruited for this part of the CHEER study through letters mailed to homes that met the low-income criteria set by Low-Income Energy Assistance Program (LEAP) in the state of Colorado. This mailing was accomplished through a partnership with Xcel Energy Inc. and Boulder Housing Partners [38]. Homes were recruited for the study only if all the home occupants were nonsmoking to eliminate smoking as a source of bias in the collected dataset.

Once a home was recruited, a home visit was conducted between the months of June through October. We focused our visits as much as possible on days when outdoor air pollution was elevated due to short- and long-range smoke from wildfires. Home visits lasted approximately two hours during which blower door tests were performed to assess home air tightness, air quality monitoring instruments were set up both indoors and outdoors, and a walk-through survey of the home was conducted noting key home characteristics. Each household was given a $\$ 25$ gift card to incentivize participation, once during instrument setup and once during instrument pickup. Prior to beginning the recruitment process, compliance approval was obtained from the University of Colorado Boulder's institutional review board (Protocol 14-0734) for performing this scientific study involving human subjects.

\subsection{Time Activity Diary}

Home occupants were asked to fill out a diary of activities in which they recorded the number of hours of spent performing specific activities during the sampling period. The activities included cooking, leaving exterior doors or windows open, running air conditioning units or swamp coolers, running kitchen or bathroom exhaust fans, and noting the times when none of the occupants were home (pets could still be home).

\subsection{Air Quality Instrumentation}

Simultaneous continuous measurements of air pollutants were taken both indoors and outdoors for two to seven days at each home. Pollutants of interest were identified based on regulatory standards and public health implications, availability of reference scientific data to validate our measurements, availability of low-cost instruments, and budget constraints. Black carbon and nitrogen dioxide were not sampled for the 2016 deployment period but were added on during the 2017 sampling campaign to capture additional data on specific traffic-related air pollutants. Figure S1 illustrates the instrumentation rigs used for indoor and outdoor sampling. No data were collected in detail regarding surrounding environment's vegetation types and crown diameters. However, outdoor monitors were positioned so that they were at least $3 \mathrm{~m}$ away horizontally from any immediate obstruction such as building walls or bushes, $10 \mathrm{~m}$ away from drip lines of trees and $1.5 \mathrm{~m}$ above ground level, attempting to follow the EPA Probe and Monitoring Path Siting Criteria for Ambient Air Quality Monitoring (40 CFR Appendix E to Part 58) [39] as far as practically possible. Indoor monitors were placed as far as possible, away from windows, fireplaces, kitchen stoves, water heaters, fans and furnaces and were positioned such that the home occupants felt comfortable getting around the instrument rigs.

To establish significant confidence in our measurements from the low-cost instruments, co-location experiments were performed with federal reference monitors from the Colorado Department of Public Health and Environment for instrument calibration as well as data validation. Figure S2 depicts the timeline of sampling and co-location periods.

\subsubsection{Particulate Matter}

Number concentrations of fine particulate matter were measured using Dylos monitors (Model 1700, Dylos Corporation, Riverside, CA, USA). Dylos-1700 is a laser-based optical particle counter that reports the number concentrations (particles per cubic centimeter, $\# / \mathrm{cm}^{3}$ ) of PM in two size bins: small particles with diameters 0.5 microns and above, 0.5 microns being the lower detection limit of the 
instrument, and large particles with diameters 2.5 microns and above. The difference between these two reported values represents the number concentration between 0.5 and 2.5 microns in particles per cubic feet (referred to from here on as $\mathrm{PN}_{0.5-2.5}$ ).

\subsubsection{Black Carbon}

Real-time black carbon (BC) data were collected using aethalometers (MicroAeth $囚 A E 51$; AethLabs, San Francisco, CA, USA), which are based on optical measurement of light transmission through a $3 \mathrm{~mm}$ spot created on a white filter strip containing insert of T60 Teflon-coated borosilicate glass fiber filter material. Each aethalometer was loaded with a fresh filter strip before sampling. Sampling frequency was set to $60 \mathrm{~s}$ and a flow rate setting of $50 \mathrm{~mL} / \mathrm{min}$ was chosen to account for the expectation of high filter loading rates for near-road outdoor sampling since most of the study homes were near highly trafficked roads (distance to the closest major road $<200 \mathrm{~m}$ ). Preliminary evaluation of time series data after sampling showed that the data had significant noise and low signal-to-noise ratio. The optimized noise-reduction algorithm developed by the United States Environmental Protection Agency [40] was used for smoothing of the time series data.

\subsubsection{Carbon Monoxide}

Custom-built open-source low-cost instruments were used for the measurement of $\mathrm{CO}$ with electrochemical sensors, temperature, and relative humidity (Y-Pods, Hannigan Lab, University of Colorado Boulder [41]). Y-Pods are based on an Arduino platform [42] with on-device data-logging capacity on a micro-SD memory card. Co-locations with reference instruments were crucial for the conversion of the raw voltage signals to meaningful pollutant concentrations. A post-processing algorithm was used for assimilating the co-location-generated calibration curves with the field data [43]. Co-location experiments were performed in both 2016 and 2017 at the Colorado Department of Public Health and Environment's Continuous Air Monitoring Program station in downtown Denver [44] for calibrating the $\mathrm{CO}$ sensors of Y-Pods. Besides CO, Y-Pods also collected data on temperature and relative humidity (data presented in the Supplementary Table S1).

\subsubsection{Nitrogen Dioxide}

Passive samplers from Ogawa Inc. (Ogawa, Pompano Beach, Florida, USA) were used for both indoor and outdoor measurement of time-weighted average concentrations of $\mathrm{NO}_{2}$. The passive sampler consists of a pre-coated sample collection paper pad coated with Triethanolamine placed inside a Teflon sampler body and secured in place by diffusion end caps. The samplers retrieved from the field were shipped to Ogawa Inc. for lab analysis along with field blanks for blank correction. Proper sampler storage, sampler preparation, and sampling protocols were followed according to the specifications from the manufacturer. All the samples were blank corrected.

\subsubsection{Instrument Rig Locations}

All the indoor instruments were set up such that they were at least two feet away from any wall, at a height of $1.5 \mathrm{~m}$, in a room free of combustion appliances, at least $1.5 \mathrm{~m}$ away from any fireplace or woodstove, and not immediately adjacent to an exterior window. Home occupants were asked not to open windows during sampling in the room where the indoor instruments were setup. Outdoor instruments were set up between 0.6 and $3 \mathrm{~m}$ away from the closest exterior wall of the homes.

\subsection{Data Filtration}

One-minute time-resolved data of $\mathrm{PN}_{0.5-2.5}, \mathrm{BC}$, and $\mathrm{CO}$ concentrations in each home indicated that indoor pollutant concentrations could spike for short periods by orders of magnitude above the outdoor level during indoor source-induced events like cooking (the indoor source events were verified with the time activity diaries filled out by the participants). Several past studies have found 
similar scenarios and have found that indoor $\mathrm{PM}_{2.5}$ concentrations are generally higher than outdoor levels [45-47].

In order to focus our analysis on impacts from outdoor pollutants and disregard indoor source effects, data filtration was performed similar to a past study from Allen et al. (2003) [46], as shown in Figure 1, in which indoor concentration spikes due to reported indoor activities such as cooking were removed from the dataset. The remainder of the data were then analyzed as a filtered set of data (referred to as "filtered data" from here on). Table S2 in the supplementary section provides comparisons between indoor and outdoor pollutants before and after data filtration.

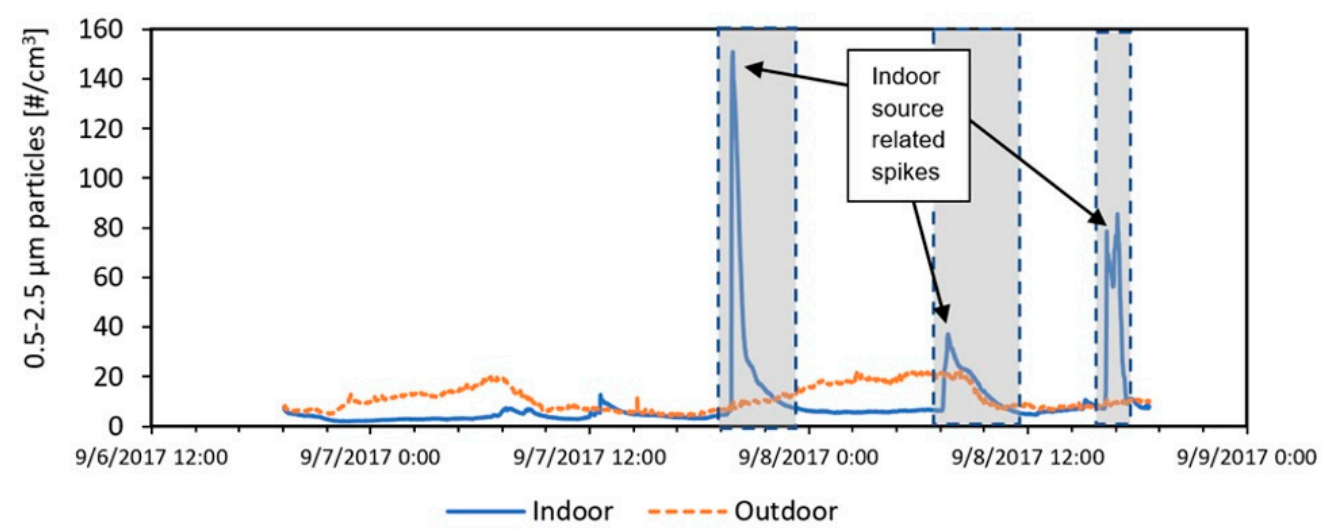

Figure 1. Example from one study home showing the data filtration process. Raw time series data from the shaded regions were removed, and the remainder of the time series was treated as "filtered data".

For $\mathrm{NO}_{2}$ data, the homes with gas stoves were not included in the assessment of the impact of outdoor pollutants because both past studies [48-50] and our data showed that homes with gas stoves had significantly higher indoor $\mathrm{NO}_{2}$ concentrations.

\subsection{Wildfire Impacts}

Remote sensing data on wildfire smoke plume PM mass density from the National Oceanic and Atmospheric Administration's Hazard Mapping System (NOAA HMS) [51] were used for categorizing the mesoscale impact level of wildfire smoke plumes on the study region. The plume PM density from the NOAA HMS is based on area coverage of wildfire-related smoke plume aerosols optically detected by NOAA satellites, and the satellite imagery is visually analyzed by experts each day. The plume was categorized into three levels of smoke-related PM densities [52]: the low category corresponds to the smoke PM density $\leq 6 \mu \mathrm{g} / \mathrm{m}^{3}$, the medium category corresponds to smoke PM density of $\leq 15 \mu \mathrm{g} / \mathrm{m}^{3}$ and high category corresponds to smoke PM density $\leq 27 \mu \mathrm{g} / \mathrm{m}^{3}$.

\subsection{Distance from the Closest Major Road}

The distance of the study homes from the closest major road was evaluated using the Online Transportation Information System database maintained by the Colorado Department of Transportation [53], where a major road is defined as a road with annual average daily traffic of greater than 10,000 vehicles [54-56]. Homes were grouped according to a distance of $<100 \mathrm{~m}, 100$ to $200 \mathrm{~m}$, and $>200 \mathrm{~m}$ from a major road based on the evidence from past studies that traffic-related air pollutant concentrations drop to background levels after moving away from a major road by between 100 and $200 \mathrm{~m}[57,58]$.

\subsection{Data Analysis}

Pollutant concentration distributions were investigated using a combination of parametric and non-parametric approaches. All pollutant concentrations were not normally or log-normally distributed (Anderson-Darling, $p<0.5)$. Hence, the non-parametric Kruskal-Wallis (K-W) and Wilcoxon 
Mann-Whitney tests were used for a statistical comparison of median pollutant concentrations. Correlations between variables are reported as Pearson's correlation coefficient (r) unless otherwise stated. All statistical analyses were performed using R programming language (Version 3.4.4, R Core Team, Vienna, Austria).

\section{Results}

\subsection{Study Household Characteristics}

Twenty-eight homes were included in the study, located in Boulder, Longmont, and Denver Colorado (Figure 2). Because of the differences observed in household demographics, the recruited home locations were separated into four major regions: Aurora (East Denver), Boulder/Longmont, West Denver, and Central/North Denver. Five homes were specially built low-income homes for improved energy efficiency by Boulder Housing Partners with airtight construction, rooftop solar panels, all-electric air heating, and water heating systems. There were two different kinds of mechanical ventilation systems observed in these five homes: three of these homes also had heat recovery ventilation, which were intermittently and automatically operated for brief periods of time each day with timer switches, and the other two homes had continuously running exhaust fans. One home was tested both years for a sample size of 10 homes during 2016 and 19 homes during the 2017 wildfire seasons. Sixteen of the homes had at least one window left open for more than twelve hours during the sampling period. Five of the homes had gas stoves, whereas 23 homes had electric stoves. Eight of the homes had stove hoods that exhausted outdoors, 13 were of the indoor recirculating type and seven homes did not have any kind of stove hood present. Table S1 summarizes key home characteristics.

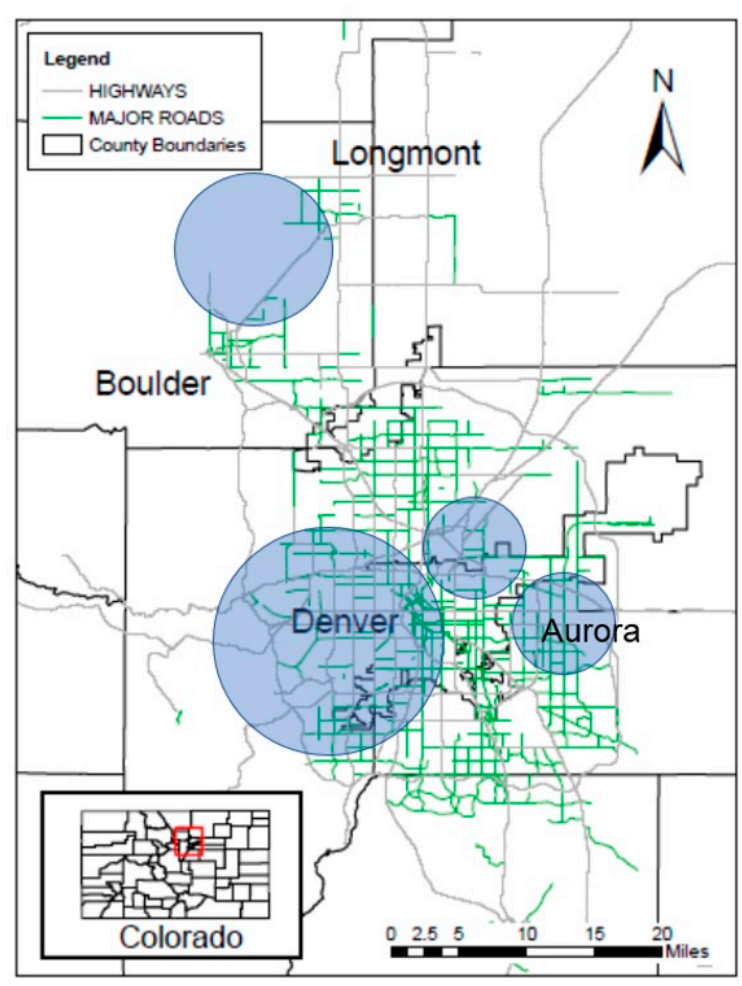

Figure 2. Map of the study region. Shaded circles indicate the areas of recruited homes and sizes of the circles indicate the approximate relative proportions of the number of homes in each area (Aurora: $N=4$, Boulder/Longmont: $N=9$, West Denver: $N=11$; Central/North Denver: $N=4$ ).

\subsection{Wildfire Impacts on Outdoor Particulate Matter in the Study Region}

$\mathrm{PM}_{2.5}$ mass concentrations recorded at Colorado Department of Public Health and Environment's Continuous Air Monitoring Program (CAMP) station in downtown Denver is illustrated as a time 
series plot in Figure 3 for the sampling periods when we deployed the air monitoring instruments in the study homes.

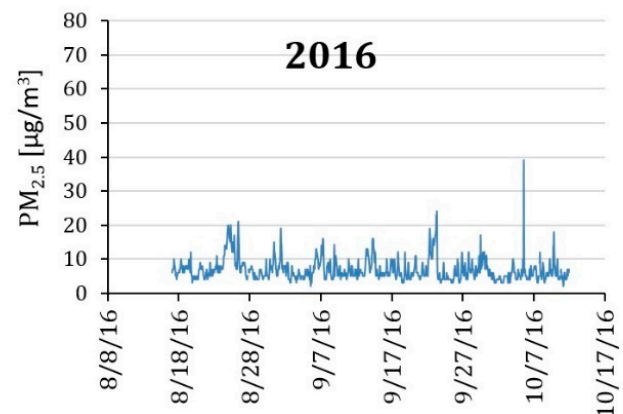

(a)

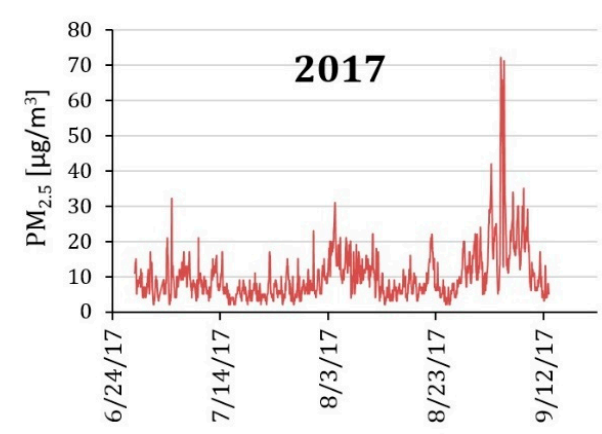

(b)

Figure 3. Time series data of particulate matter $\left(\mathrm{PM}_{2.5}\right)$ concentration measurements made at Colorado Department of Public Health and Environment's Continuous Air Monitoring Program (CAMP) station in Downtown Denver during our instrument deployment periods in (a) 2016 and (b) 2017.

There were a few spikes of elevated $\mathrm{PM}_{2.5}$ concentrations, particularly towards the end of the 2017 sampling period. These periods coincided with several days of reduced visibility due to long-range wildfire plumes from Canada and the Western regions of the United States, which was confirmed using NOAA HMS satellite imagery for the time periods corresponding to the pronounced spikes. The summer of 2016, however, had comparatively low outdoor $\mathrm{PM}_{2.5}$ during our field deployment period. Both 2016 and 2017 deployment periods had several days of outdoor $\mathrm{PM}_{2.5}$ levels above the primary one-year National Ambient Air Quality Standard for $\mathrm{PM}_{2.5}$ of $12 \mu \mathrm{g} / \mathrm{m}^{3}$. Typically, the Denver metro area complies with the $\mathrm{PM}_{2.5}$ standard [59].

Study homes were categorized according to the wildfire-related plume cover density in the study region during the instrument deployment period. Categorization of plume cover over the study region corresponded well with the ground level measurements taken at the CAMP air monitoring station in Denver (Figure 4). The CAMP hourly measurements of $\mathrm{PM}_{2.5}$ monotonically increased from a median concentration of 6 to $8(+33 \%), 8$ to $12(+50 \%)$ and 12 to $23 \mu \mathrm{g} / \mathrm{m}^{3}(+92 \%)$ between the plume categories None, Low, Medium, and High, respectively (K-W test: $p<0.05)$. The median difference between the High and None categories was $17 \mu \mathrm{g} / \mathrm{m}^{3}$, which was 2.8 times the background level (representative of traffic and other local emission sources) of $6 \mu \mathrm{g} / \mathrm{m}^{3}$.

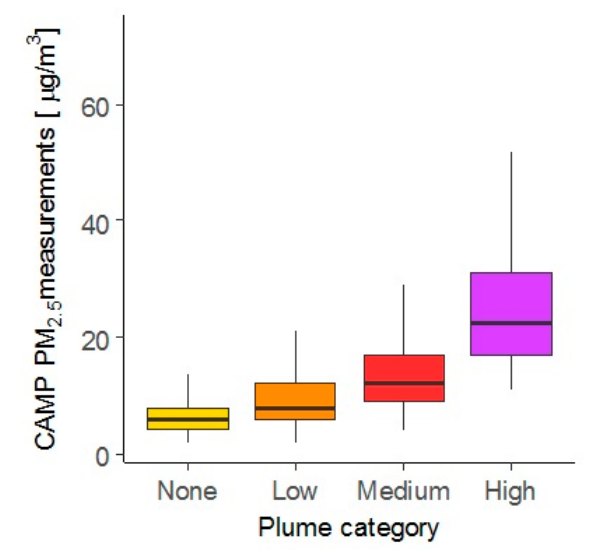

Figure 4. Boxplots (without outliers) showing plume categories and the corresponding $\mathrm{PM}_{2.5}$ concentration measurements made at Colorado Department of Public Health and Environment (CDPHE)'s Continuous Air Monitoring Program (CAMP) air monitoring station in Denver. Data were pooled together from the deployment periods from 17 August 2016 to 10 October 2016 and from 28 June 2017 to 12 September 2017. (Kruskal-Wallis (K-W) test: $p<0.01$.) 


\subsection{Indoor and Outdoor Pollutant Measurements}

\subsubsection{Data Capture}

The number of homes for which data were available for each measured pollutant varied due to data recovery issues; some instruments suffered from power failure, sensor malfunction, or some other technical issue that prevented data capture. Out of the 29 times when our instruments were deployed to record data (measurement in one home was taken both in 2016 and 2017, resulting in our dataset of 29 unique measurements done in 28 different homes), the total number of homes for which data were available both indoors and outdoors ranged between 17 and 27 homes. $\mathrm{BC}$ and $\mathrm{NO}_{2}$ measurements were only added in 2017, whereas the rest of the pollutants were measured for both 2016 and 2017 periods. Table S3 summarizes the measured pollutant concentrations indoors and outdoors from raw datasets.

\subsubsection{Particulate Matter}

Raw time series data of indoor and outdoor $\mathrm{PN}_{0.5-2.5}$ captured by the Dylos monitors showed that outdoor concentrations were mostly higher than indoor concentrations except when there were spikes in the indoor concentrations caused by indoor activities like cooking. This was true even in the absence of wildfire plumes. The fraction of sampling times when outdoor concentrations were higher than indoors during each field deployment was 59\% of the cumulative total sampling time in all the homes.

Figure 5 shows an example of the time series of $\mathrm{PN}_{0.5-2.5}$ concentrations from two of the homes. In Figure 5a, one cooking-related spike can clearly be seen in the indoor $\mathrm{PN}_{0.5-2.5}$ concentration. The field deployment period for this home coincided with a plume cover event of medium density, which explains the distinct rise in outdoor $\mathrm{PN}_{0.5-2.5}$ concentrations compared to background levels, lasting for roughly six to seven hours at a time. The occupants of this home kept a window open at all times during testing. This pattern was also seen in other homes and the profiles of indoor concentrations were seen to follow the outdoor concentration spikes in most cases.

The home shown in Figure $5 \mathrm{~b}$ had no significant indoor sources during sampling. All the windows in this home were closed throughout the sampling period. The significant elevation of outdoor $\mathrm{PN}_{0.5-2.5}$ concentration period in the first half of the sampling period also coincided with a plume cover event of medium density over the study region.

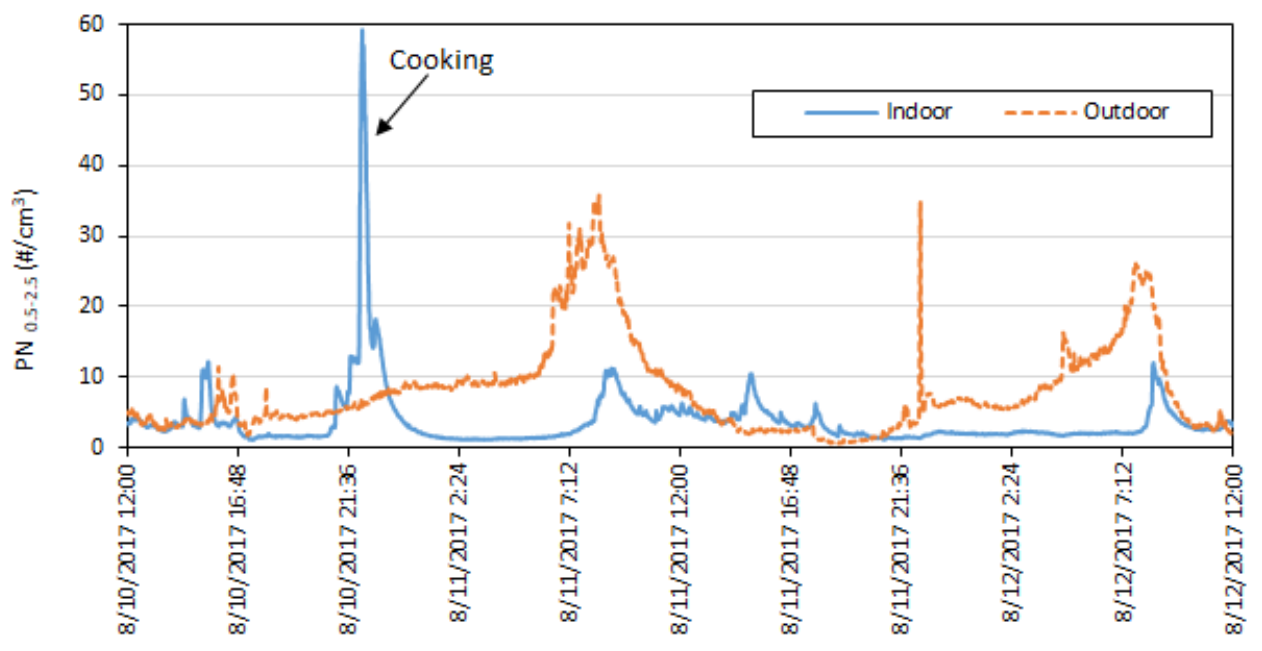

(a)

Figure 5. Cont. 


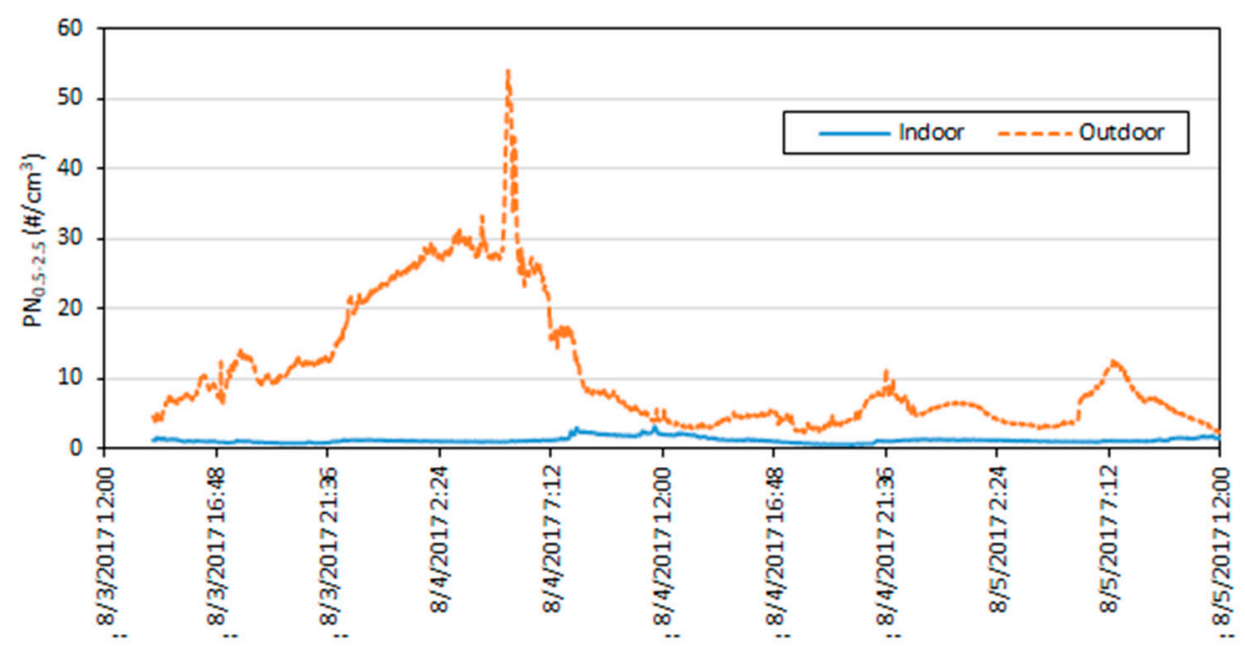

(b)

Figure 5. Indoor and outdoor time series $\mathrm{PN}_{0.5-2.5}$ data from two of the homes tested ( (a): Home T442, (b): Home T450).

\subsubsection{Black Carbon}

Black carbon was measured only during the 2017 campaign. Time series of outdoor and indoor BC time series profiles (raw datasets) from one of the homes tested with home identification number (Home ID) T109 are shown in Figure 6. Table S2 shows that Spearman's rank correlation between indoor and outdoor BC were positively correlated $\left(r_{S}=0.51, p<0.000\right)$. Outdoor BC was also correlated with outdoor $\mathrm{PN}_{0.5-2.5}\left(\mathrm{r}_{\mathrm{s}}=0.56, p<0.000\right)$. Very few homes had indoor source-related spikes, suggesting that most of the $\mathrm{BC}$ in homes originated outdoors. A past study has also shown that outdoor vehicular traffic emissions directly affect indoor BC levels despite windows remaining closed at all times [60]. Outdoor BC concentrations were higher than indoors $66 \%$ of the total sampling time in all homes.

The effect of window opening on BC concentrations can clearly be seen from Figure $6 \mathrm{~b}$. The outdoor BC concentration spike at 00:00 on 30 June 2017 that lasted for at least one hour had no effect on the indoor $\mathrm{BC}$ concentration because the windows were closed at night. During the daytime, however, the windows were left open and the indoor concentrations closely followed the outdoor profiles.

\subsubsection{Carbon Monoxide}

The carbon monoxide levels measured in this study were low, averaging $0.69 \mathrm{ppm}$ indoors and $0.20 \mathrm{ppm}$ outdoors (raw dataset). A total of 12 homes had indoor and outdoor concentrations that were similar, while 16 other homes had higher indoor average levels of $\mathrm{CO}$. Three of these homes with higher indoor $\mathrm{CO}$ also had gas stoves. Only two out of the 28 homes sampled had electric water heaters, whereas the remainder of the homes had gas water heaters with standing pilot lights. A total of 25 of the homes also had forced air heating systems using natural gas as fuel.

\subsubsection{Nitrogen Dioxide}

Nitrogen dioxide was measured only during the 2017 campaign. Three homes with gas stoves had significantly high indoor $\mathrm{NO}_{2}$ compared to outdoors (Figure 7; T134, T109, T288). The median indoor concentration of $\mathrm{NO}_{2}$ was roughly three times higher, and the indoor/outdoor $\mathrm{NO}_{2}$ ratio was 2.3 in these homes with gas stoves compared to 0.98 in the homes without gas stoves, a result not likely due to chance (K-W test, $p=0.007$ : Table S3). These homes were not included in the subsequent data analysis of outdoor $\mathrm{NO}_{2}$ infiltration. In the rest of the homes, indoor and outdoor concentrations of $\mathrm{NO}_{2}$ were comparable to each other and not impacted by wildfire plumes. In all cases, the concentrations of $\mathrm{NO}_{2}$ were lower than the National Ambient Air Quality Standard (NAAQS) of 53 ppb. 


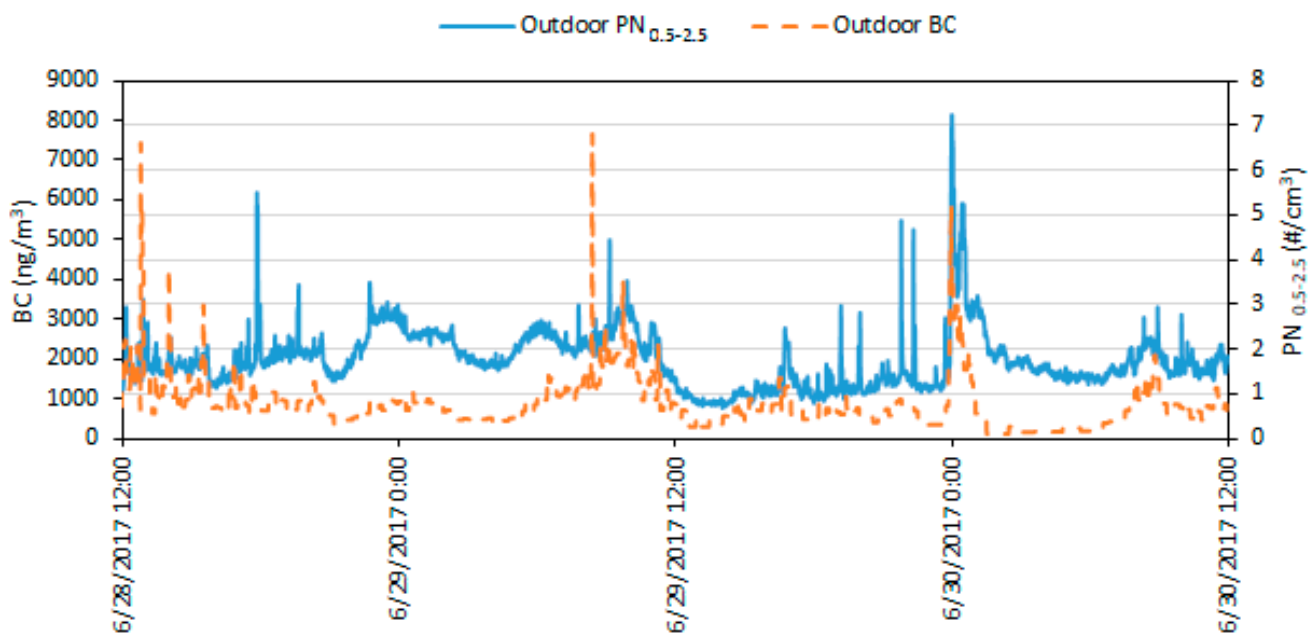

(a)

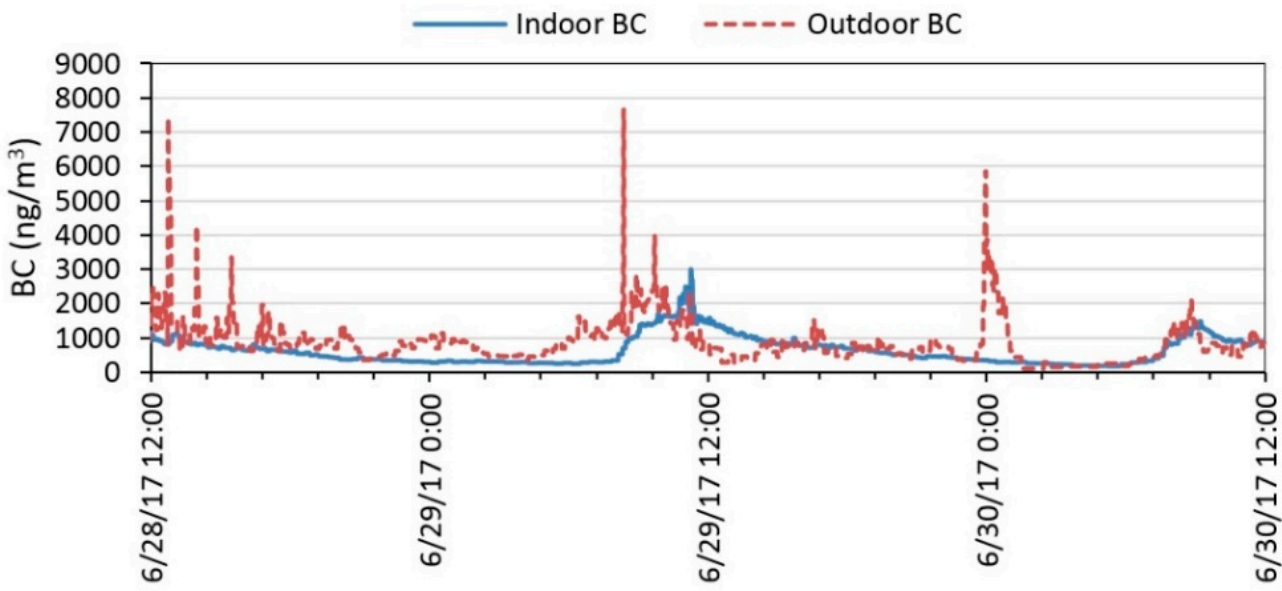

(b)

Figure 6. Time series profiles of black carbon from one of the test homes (Home ID: T109). (a) Compares the outdoor concentration profiles of black carbon (BC) and $\mathrm{PN}_{0.5-2.5}$, and (b) compares the indoor and outdoor BC profiles.

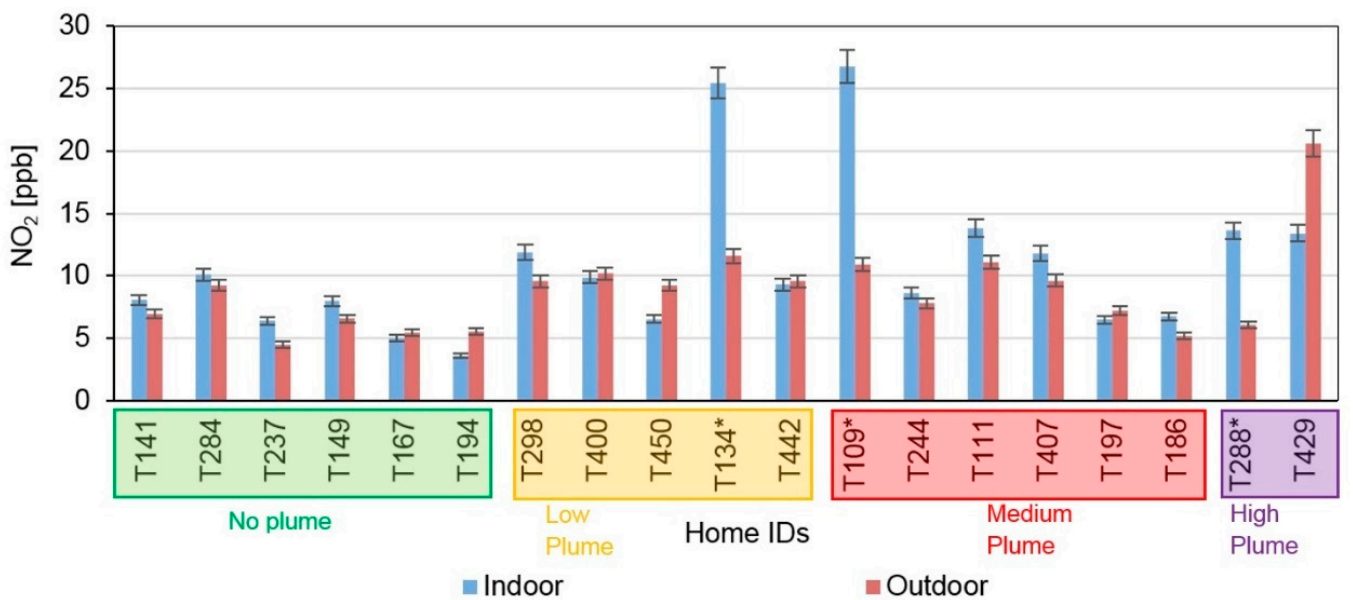

Figure 7. $\mathrm{NO}_{2}$ concentrations measured in 2017 in all homes $(n=19)$. Home IDs with asterisk represent homes with gas stoves. Error bars indicate sampler uncertainty. Homes are ordered from left to right with increasing wildfire plume densities during sampling. 


\subsection{Impacts of Road Proximity}

Outdoor pollutant concentrations monotonically decreased with increasing distance from the closest major road, a finding in good agreement with a number of previous studies [61-63]. It was noted in our study, however, that the geometric means of $\mathrm{PN}_{0.5-2.5}, \mathrm{BC}$, and $\mathrm{NO}_{2}$ outdoor concentrations had more significant decline than $\mathrm{CO}$ with increasing distance from the major road (Figure 8). Exponential curve-fitting was used in Figure 8 for comparability with past studies and exponential nature of general air pollutant dispersion phenomenon [64-67]. Outdoor and indoor $\mathrm{NO}_{2}$ concentrations rose monotonically and almost identically with respect to the distance from the closest major road. Indoor median $\mathrm{PN}_{0.5-2.5}$ was $15 \%$ higher in homes located closer to the roads.

$(n=26)$

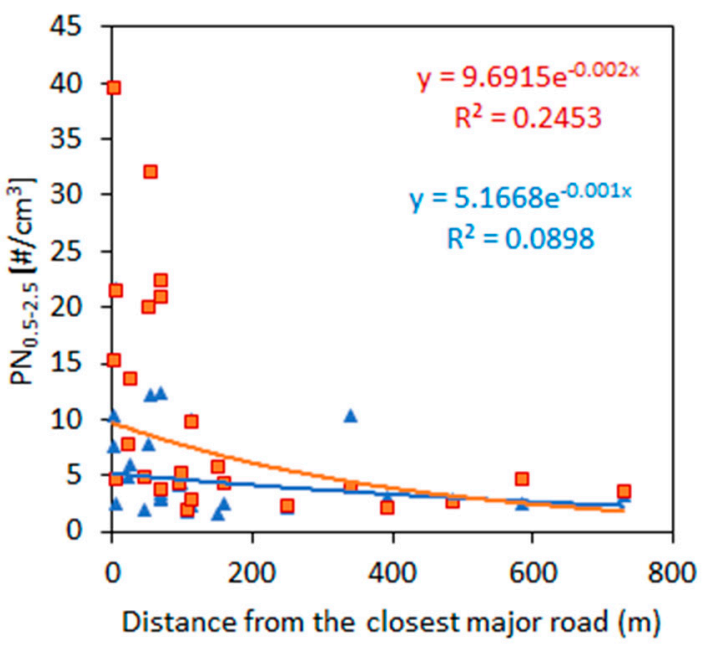

(a)

$(n=16)$

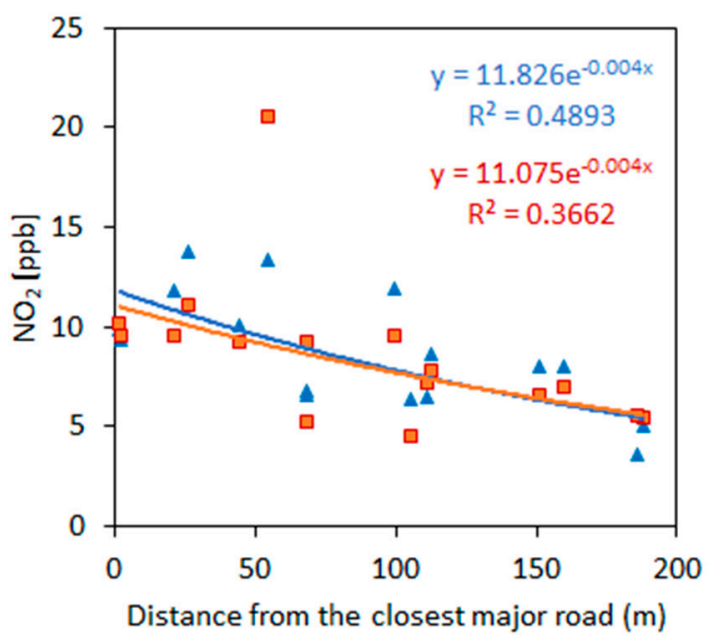

(c)

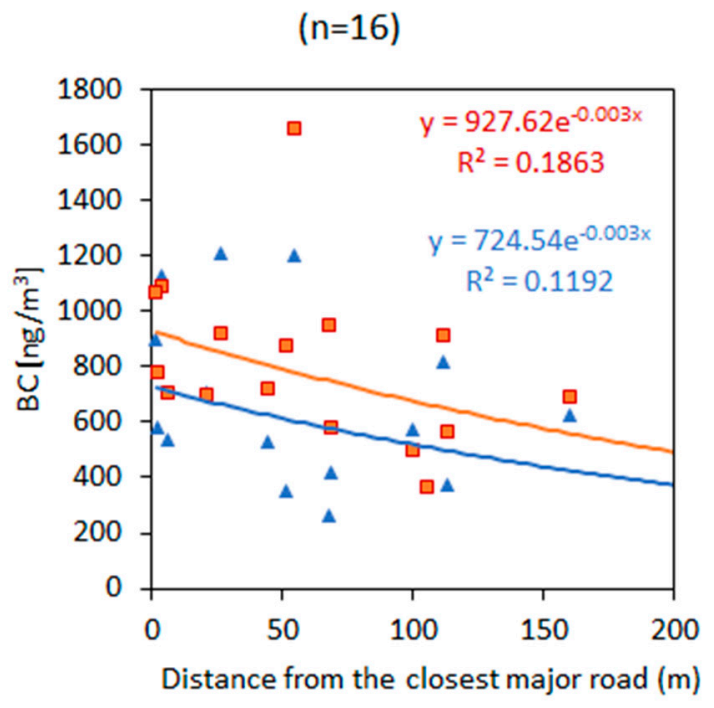

(b)

$(n=27)$

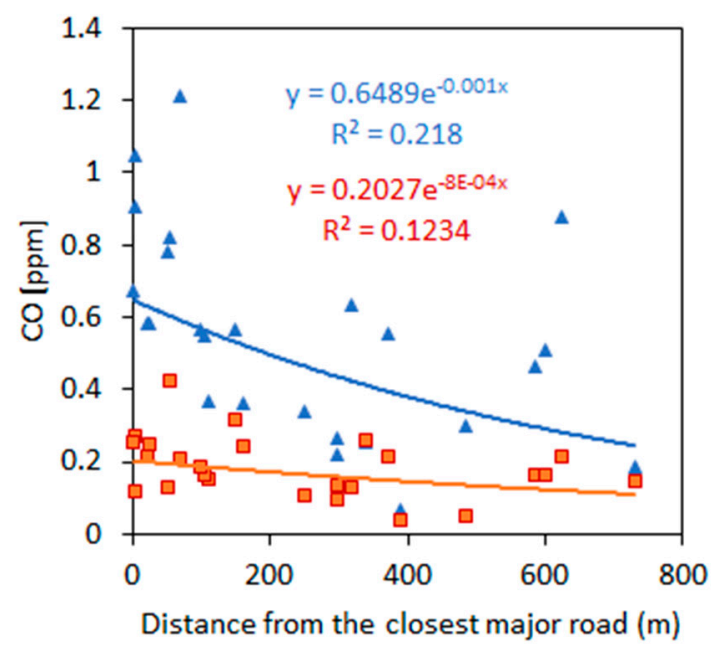

(d)

$$
\begin{array}{ll}
\Delta \text { Indoor } & \square \text { Outdoor } \\
\text { —Expon. (Indoor) } & \text { Expon. (Outdoor) }
\end{array}
$$

Figure 8. Pollutant concentrations as a function of distance from the closest major road (exponential curve-fitting) for (a) $\mathrm{PN}_{0.5-2.5}$, (b) BC, (c) $\mathrm{NO}_{2}$, (d) $\mathrm{CO}$. This dataset does not include the three homes with gas stoves. 


\subsection{Filtered Indoor and Outdoor Measurements}

After filtering the datasets for indoor pollution-generating activity spikes, the median indoor/outdoor (I/O) ratios of $\mathrm{CO}$ and $\mathrm{NO}_{2}$ were greater than one (Figure 9), whereas for $\mathrm{PN}_{0.5-2.5}$, and $\mathrm{BC}$ they were less than one, which was also seen with the raw datasets. Indoor $\mathrm{CO}$ concentrations in the homes were two to four times the outdoor concentrations. Indoor median $\mathrm{CO}$ concentrations were close to 1 ppm in most homes (raw data) and well below the eight-hour NAAQS for CO of 9 ppm. Indoor $\mathrm{CO}$ concentrations in four homes were often elevated above 1 ppm and the median indoor $\mathrm{CO}$ concentration for these homes ranged from 1.5 to $3.1 \mathrm{ppm}$. Three of these homes had gas stoves, while the fourth did not. Eleven homes had elevated levels of $\mathrm{CO}$ (three to five times higher indoors compared to outdoors), even when indoor source-related spikes were filtered out as reported in the time-activity diaries.

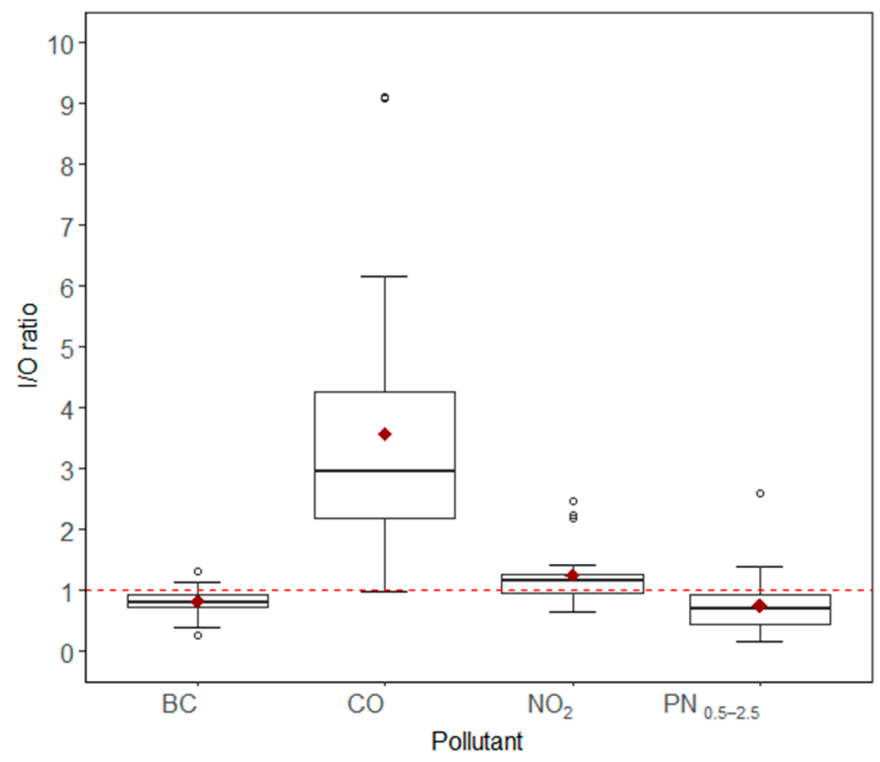

Figure 9. Tukey boxplot showing indoor/outdoor ratios of all pollutants calculated from filtered dataset. Lower and upper bounds of the boxplot represent first quartile and third quartiles (Q1 and Q3, respectively; middle bar inside the box represents the median, middle diamond inside the box represents the mean value, lower and upper whisker limits indicate Q1 - 1.5x (inter-quartile range) and Q3 + 1.5x (inter-quartile range), respectively, and the dots outside the whisker limits indicate outliers.

Wildfire plumes caused a significant rise in the median outdoor as well as indoor concentrations of most pollutants (Figure 10). Outdoor median $\mathrm{PN}_{0.5-2.5}$ was 6.4 times higher and indoor median $\mathrm{PN}_{0.5-2.5}$ was 3.6 times higher during the High plume cover compared to the times with no plume cover. The I/O ratio was the highest for $\mathrm{CO}$ in the High plume category and was 35\% higher than the None category, indicating some $\mathrm{CO}$ was due to the smoke plume. In the absence of any wildfire plumes, outdoor median concentrations of $\mathrm{PN}_{0.5-2.5}$ and $\mathrm{BC}$ were 1.6 and 1.4 times higher than indoors, respectively, which can mostly be attributed to traffic-related emissions in the absence of other significant local outdoor and indoor sources. Wildfire plumes did not affect $\mathrm{NO}_{2}$.

Table S4 in the supplementary section presents comparisons between indoor and outdoor medians and ranges for various measured pollutant concentrations (from the filtered dataset) classified according to house characteristics. The location of the homes significantly affected pollutant concentrations and $\mathrm{I} / \mathrm{O}$ ratios. Homes built in the Aurora region had the lowest median I/O ratios for $\mathrm{PN}_{0.5-2.5}$ and $\mathrm{BC}$, whereas I/O for CO was highest in Aurora. Homes in Central/North Denver regions had the highest outdoor median concentrations of $\mathrm{PN}_{0.5-2.5}$ and BC. 


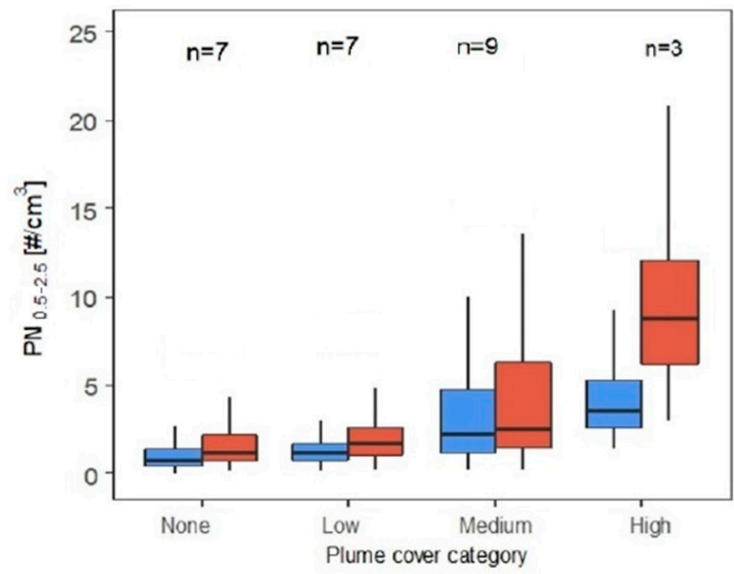

(a)

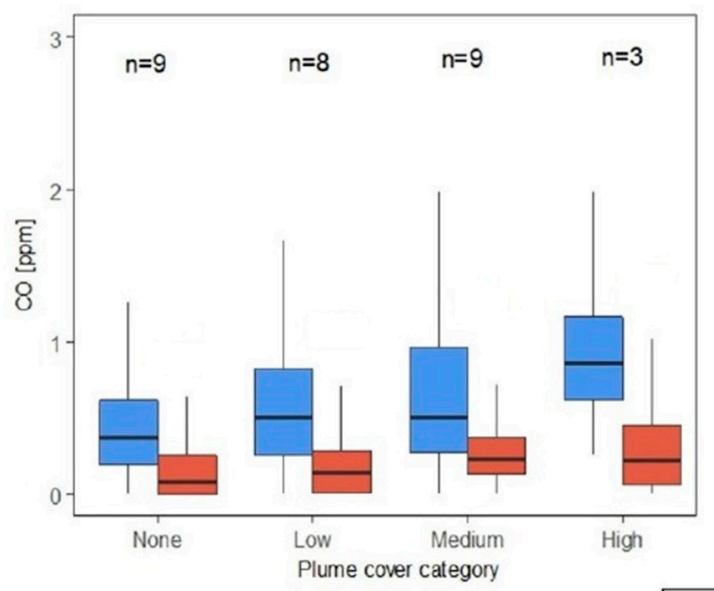

(c)

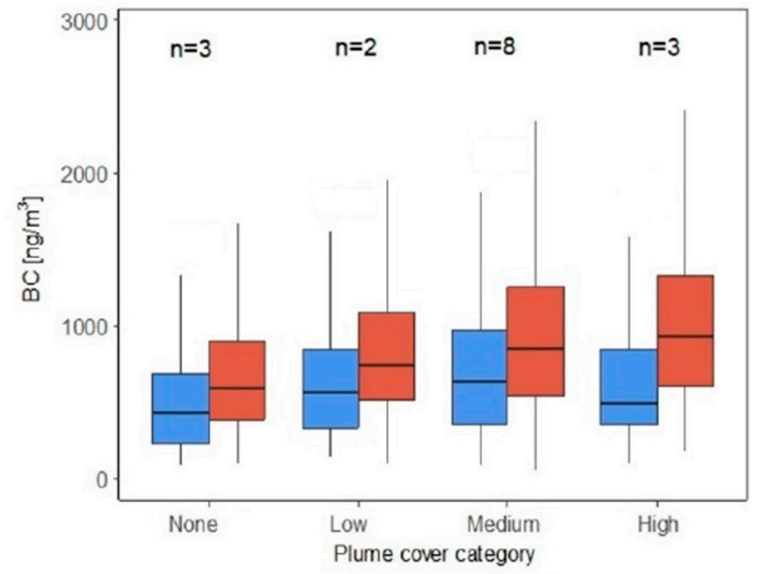

(b)

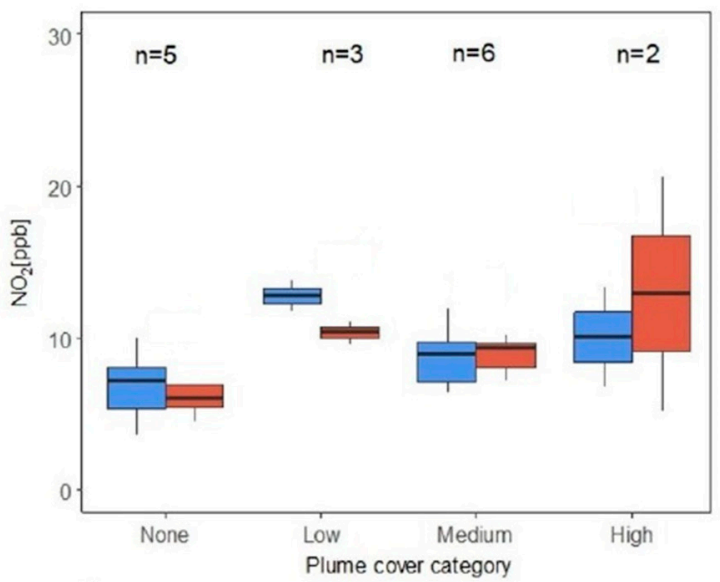

(d)

Figure 10. Indoor and outdoor pollutant concentration distributions (not showing outliers) according to wildfire plume cover (filtered datasets) for (a) $\mathrm{PN}_{0.5-2.5}$, (b) $\mathrm{BC}$, (c) $\mathrm{CO}$ and (d) $\mathrm{NO}_{2}$. The indoor and outdoor concentrations between all plume categories were significantly different for all pollutants except $\mathrm{NO}_{2}(\mathrm{~K}-\mathrm{W}$ test at $\alpha=0.05)$.

With respect to mechanical ventilation (MV), the median $\mathrm{I} / \mathrm{O}$ ratio of $\mathrm{PN}_{0.5-2.5}$ and $\mathrm{BC}$ were higher by $18 \%$ and $4 \%$, respectively, when MV was present, indicating that the outdoor air pollution was brought indoors through ventilation supply air and not adequately filtered out. The MV systems only had low efficiency filters designed primarily to protect the equipment and not intended to provide clean air supply to the conditioned zone. The median $\mathrm{I} / \mathrm{O}$ ratio of $\mathrm{CO}$ was lower in homes with MV by $3 \%$ indicating the ventilation removed the indoor $\mathrm{CO}$.

The impact of gas stoves was seen even in the filtered datasets. Although homes with gas stoves were not included in the $\mathrm{NO}_{2}$ dataset, the rest of the pollutant datasets still included the homes with gas stoves. The I/O ratios for $\mathrm{CO}$ were significantly higher $(+57 \%)$ in homes with gas stoves.

The type of kitchen stove hood also had a significant impact on indoor pollutant concentrations. In the filtered datasets, the homes with exhaust type stove hoods had $\mathrm{PN}_{0.5-2.5} \mathrm{I} / \mathrm{O}$ ratios $49 \%$ less than the homes with recirculating hoods and $55 \%$ less than the homes with no stove hoods installed.

Home occupants relied on window opening for thermal comfort, mainly because they did not have air-conditioning, resulting in almost instantaneous transfer of pollutants between outdoors and indoors. The time-activity diary revealed that most homes (25 out of 28$)$ had at least one window open 
for at least one hour a day. Indoor median BC concentration had a monotonic rise with the number of hours of at least one window open in the house. However, a similar rise was not seen with $\mathrm{PN}_{0.5-2.5}$ (Figure 11). Window opening also had a significant impact on the I/O ratio of $\mathrm{CO}$, with the highest $\mathrm{I} / \mathrm{O}$ ratio for the homes that had all the windows closed throughout the sampling period, which was roughly three times higher than having the window open for even a small fraction of the time.

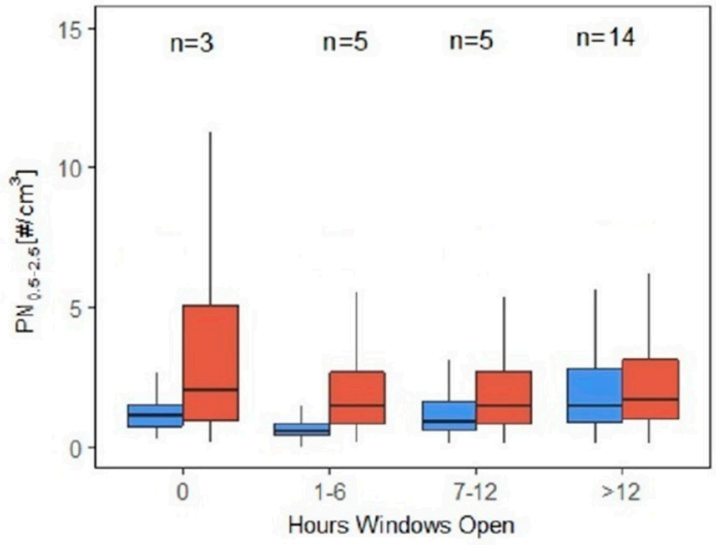

(a)

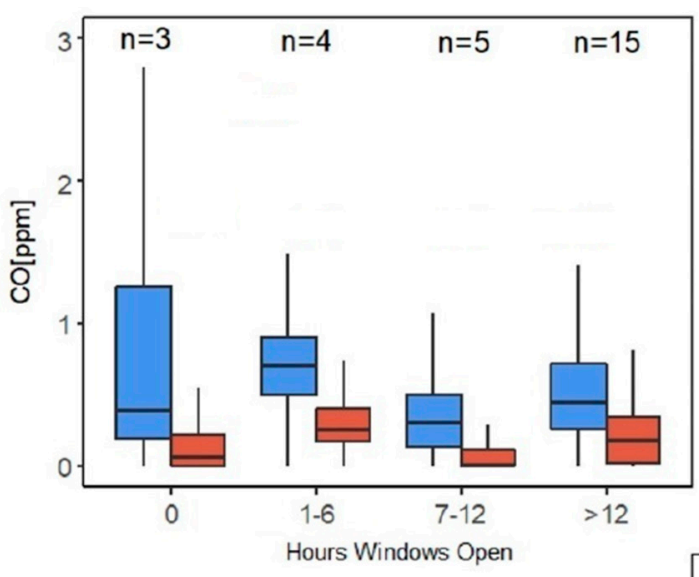

(c)

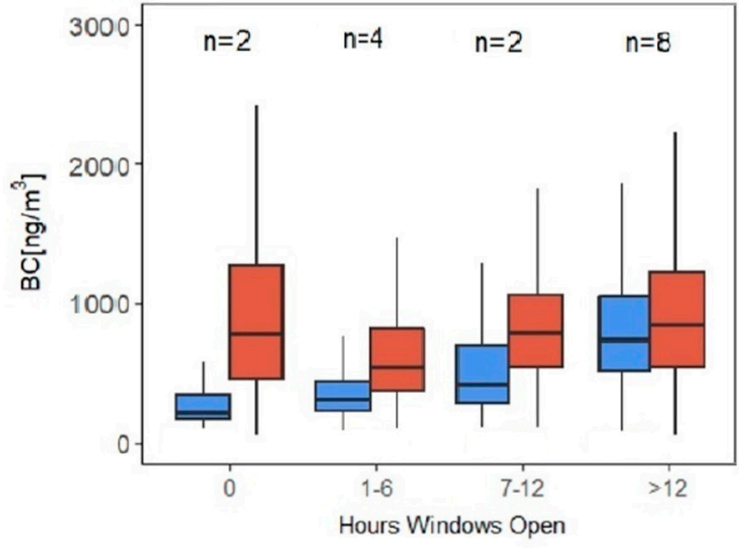

(b)

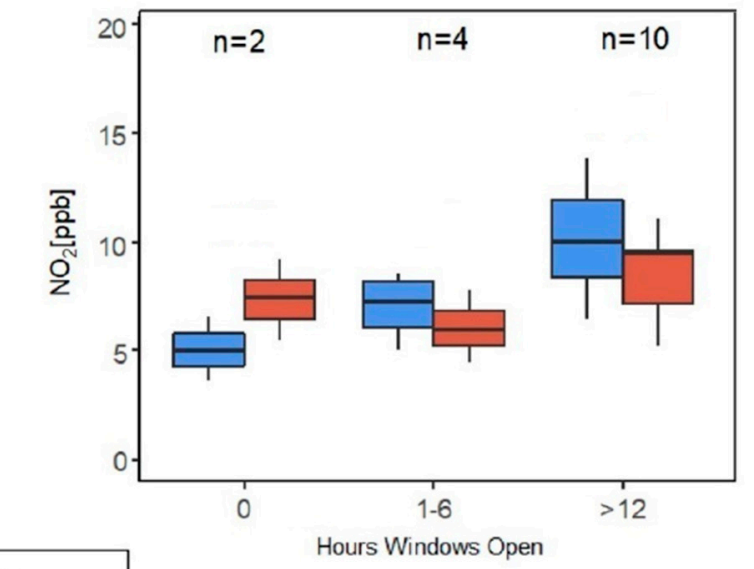

(d)

Figure 11. Indoor and outdoor pollutant concentration distributions (not showing outliers) according to the hours of window opening (filtered dataset) for (a) $\mathrm{PN}_{0.5-2.5}$, (b) BC, (c) $\mathrm{CO}$ and (d) $\mathrm{NO}_{2}$. The indoor and outdoor mean concentrations were significantly different across all window opening intervals for all pollutants except for $\mathrm{NO}_{2}(\mathrm{~K}-\mathrm{W}$ test at $\alpha=0.05)$.

\section{Discussion}

The main objective of this study was to investigate the impact of outdoor pollution on indoor air quality during wildfire seasons in Colorado. Data filtering was performed to remove the spikes in indoor concentrations of all the pollutants from indoor sources or activities, which were mostly cooking related. Spearman's rank correlations (r) were also calculated between indoor and outdoor concentrations for both raw and filtered data. Filtering the data changed the concentration distributions of all indoor pollutants. The median indoor concentrations of $\mathrm{PN}_{0.5-2.5}, \mathrm{CO}$, and $\mathrm{BC}$, due to data filtration were reduced by $16 \%, 7 \%$, and $4 \%$ respectively; differences were statistically significant for $\mathrm{PN}_{0.5-2.5}$ and $\mathrm{CO}$, suggesting that cooking indoors was a significant source of $\mathrm{PN}_{0.5-2.5}$ and $\mathrm{CO}$. Table S2 in the supplementary section summarizes the comparison between raw and filtered datasets. Table S4 presents the I/O ratios, based on the filtered dataset. 
While the indoor/outdoor ratio was used in this study as an effective metric for a comparison of pollutant concentrations between indoors and outdoors, it should be noted that the I/O ratio can decrease not just because of the decrease in indoor concentration, but also due to an increase in outdoor concentration (or a combination of both). Hence, it is important to also refer to the median indoor and outdoor concentrations to help elucidate associations. Median values are reported here instead of arithmetic means because of their robustness towards outliers. The I/O ratios and concentrations of all pollutants were positively skewed but not log-normally distributed (A-D test: $p<0.000$ ).

Our results showed that 11 homes had indoor concentrations of $\mathrm{CO}$ three to five times higher than outdoors even when indoor source-related spikes (as determined from time activity diaries) were filtered out from our dataset. One possible explanation to this observation is the effect of standing pilot lights in combustion devices like gas water heaters and fireplaces. All the homes we studied had CO alarms installed properly, and were in working condition, and all the levels measured were well below the one-hour NAAQS for CO of $35 \mathrm{ppm}$, so the occupants were not in immediate danger of acute $\mathrm{CO}$ poisoning during our sampling. The health impacts of chronic exposure to lower levels of $\mathrm{CO}$ are less clear [68]. Potential links between ambient levels of $\mathrm{CO}$ and behavioral abnormalities in children and effects of subclinical exposure on the brain during development have been discussed [69]. A study of elderly men showed increased carboxyhemoglobin levels in subjects who used gas for cooking [70]. More research should be done to determine whether these results are more widespread in homes so that better venting of combustion appliances can be addressed by introducing appropriate building codes that require mandatory outdoor venting of gas stoves.

Data from our study are consistent with previous studies in many respects. Previous studies of indoor and outdoor particulate matter in buildings in the front range of Colorado show that concentrations depend on location, and that concentrations are typically higher in Denver compared to less urban cities such as Boulder [71]. A study of 15 homes in Boulder/Ft. Collins measured $\mathrm{PM}_{2.5}$ concentrations that were highest during the summer. Our measurements of $\mathrm{NO}_{2}$ outdoor concentrations from the raw dataset are also in agreement with a study using the same sampler that shows an exponential rise in outdoor $\mathrm{NO}_{2}$ with decreasing distance to a major road [72]. Our finding of indoor $\mathrm{NO}_{2}$ concentrations being two to three times higher in homes with gas stoves is also consistent with past studies [73,74]. In a previous study, BC concentration ranged from 3.4 to $10 \mu \mathrm{g} / \mathrm{m}^{3}$ at a distance of $30 \mathrm{~m}$ from an interstate highway, and closely tracked the concentration profiles of particulate matter and $\mathrm{CO}$ [75]. These levels are higher than what was measured in this study: we measured peaks of $1.2-1.6 \mu \mathrm{g} / \mathrm{m}^{3}$.

As many previous studies have found, indoor sources cause peaks in indoor pollutant concentrations. However, traffic and wildfire pollutants add to the levels observed indoors. Filtering the dataset to remove obvious indoor source-related spikes in concentrations of the pollutants gave a better picture of how building shells generally interact with the outer environment. The correlations between indoor and outdoor pollutant concentrations were higher when the dataset was filtered (Table S2), indicating that filtering achieved our objective of reducing the data to reflect the outdoor contribution to indoor concentrations. The building envelope is intuitively thought of as the protective layer between the indoor environment and outdoor air pollution. Our data suggest that even without indoor sources, median indoor concentrations of $\mathrm{CO}$ can be elevated by up to three-fold during when wildfire plumes are impacting local outdoor air and by four-fold due to roadway proximity although indoor concentrations of $\mathrm{PN}_{0.5-2.5}$ and $\mathrm{BC}$ were found to be less than or close to outdoor concentrations during wildfire plumes as well as close proximity to the roads (Table S4). Past studies have identified that even when windows remain closed the indoor PM levels are directly affected to a measurable extent by outdoor PM concentrations. Window opening behavior in response to temperature changes add to the introduction of outdoor PM indoors, especially in low-income communities who have no easy access to air conditioning and indoor air filtration technologies [76,77].

There were also a number of limitations in our study. Due to the nature of the study, very strict recruitment criteria could not be implemented, for example homes with the exact same layout, 
or number of exterior doors and windows. Hence, homes recruited were randomized in terms of the number and sizes of windows, building materials, etc. Despite the attempt to collect outdoor meteorological data from homes, the data retrieval rate from Y-Pods was very low for the weather station connected to the Y-Pods. Hence, no statistical comparisons could be made between pollutant $\mathrm{I} / \mathrm{O}$ ratios and wind speeds. Also, the study was conducted during the summer season and the majority of the home occupants resorted to opening windows for thermal comfort. This meant that we could not associate the pollutant concentrations indoors to the air tightness of the building shell structure. Natural ventilation rates have been shown to have an impact on indoor fine PM deposition rate, which can result in different indoor exposure levels in case occupants have all windows closed during wildfire plume events [78]. Hence, future studies can incorporate studying the impact of the leakage of building shell structure on pollutant $\mathrm{I} / \mathrm{O}$ ratios in low-income households.

Low-income households in the U.S. can benefit from this study in a number of ways with respect to the improvement in public health. High indoor concentration spikes of pollutants associated with indoor sources like cooking are difficult to avoid in real-life, thus to reduce exposure better strategies can be implemented to ensure protection from outdoor air pollution in low-income homes, such as installing cooling devices so that windows can remain closed during pollution episodes and distributing air cleaners on especially polluted days. As seen from Tables S3 and S4, I/O ratios for $\mathrm{PN}_{0.5-2.5}$ were highest for homes without kitchen stove hoods, followed by homes with recirculating stove hoods when compared to exhaust-type stove hoods, a finding in agreement with another study [79]. Indoor source-related emissions should still be addressed with engineering approaches such as source control (stove exhaust hoods) or other strategies to reduce air pollutant exposure. The I/O ratio for temperature is almost always greater than one and the $\mathrm{I} / \mathrm{O}$ ratio for relative humidity is almost always less than or close to one in all homes (Table S1). This means that air tends to get drier as it infiltrates indoors into the residential indoor spaces. Logically speaking, this tendency can increase the ultrafine fraction of suspended particulate matter after infiltrating as the volatile part of the PM evaporates under the drier conditions, thus reducing the PM aerodynamic diameter. Homes close to major roads and highways are particularly more vulnerable to having more ultrafine particulate matter infiltration, hence, resulting in greater public health concerns. For new housing developments close to the highways, ventilation options should be carefully analyzed to minimize the introduction of traffic-related PM to the indoor air by facing ventilation air intakes on the sides of the buildings away from the highways [80] and utilizing filtration. In addition, smart low-cost sensor technologies have a huge potential to provide greater control over the active ventilation of residential spaces. The reduction in occupant exposure to outdoor air pollution by collective knowledge and the careful use of ventilation techniques will ultimately result in better public health of low-income communities who are vulnerable to the health risk impacts of outdoor air pollution.

\section{Conclusions}

This study showed that outdoor air pollution related to traffic emissions and wildfires significantly increased the indoor air pollutant concentrations due to infiltration and natural ventilation in the 28 low-income homes that were sampled. Wildfires increased the $\mathrm{PN}_{0.5-2.5}$ indoors by almost four times, and $\mathrm{BC}$ by almost two times, compared to when there were no wildfires. Proximity to roadways influenced indoor concentrations of $\mathrm{BC}, \mathrm{CO}$, and $\mathrm{NO}_{2}$, significantly elevating the concentrations in homes closest to roadways compared to those more than $200 \mathrm{~m}$ away. Among the various pollutants measured, the I/O ratio of CO was found to be consistently two to three times higher than other pollutants measured. Regarding the factors affecting indoor pollutant concentrations, window opening significantly increased BC concentrations, but decreased $\mathrm{CO}$ concentrations. Indoor $\mathrm{NO}_{2}$ concentrations were found to be over two times higher compared to outdoors in the homes with gas stoves. Homes with exhaust hoods had lower indoor pollutant concentrations, while the homes with MV systems, although few in number, were found to have consistently higher levels of the measured pollutants indoors. 
Supplementary Materials: The following are available online at http://www.mdpi.com/1660-4601/16/19/3535/s1, Figure S1: Outdoor instrument rig (Left) and Indoor Instrument rig (Middle and Right). [Legend for labels: $1=$ Weather station; 2 = Dylos-1700 Monitor (outdoor instrument covered with metallic bucket); $3=$ microAeth AE51 Aethalometer (outdoor instrument covered with metallic bucket); $4=$ Y-pod; 5 = Ogawa NO2 passive sampler; 6 = weather-protected electrical connection point; 7 = tripod stand.], Figure S2: Schematic showing timeline of instrument deployment periods, sensor calibration periods for Y-Pods and validation periods for sensor calibrations. CO2 data were calibrated using TSI Q-Trak as the reference instrument, but the data showed poor results during validation and, hence, $\mathrm{CO} 2$ data were discarded, Figure S3: Example of National Oceanic and Atmospheric Administration's Hazard Mapping System (NOAA HMS) remote sensing data showing a day with plume cover (a) and no plume cover (b) over the state of Colorado, Table S1: Cross-tabulation of indoor and outdoor temperature and relative humidity with various home characteristics (raw dataset). Total $N=28$, Table S2: Concentration comparisons between indoor and outdoor pollutants before and after data filtration, Table S3: Pollutant concentrations indoors and outdoors from raw datasets with the corresponding p-values from $\mathrm{K}-\mathrm{W}$ test on I/O ratios between categories, Table S4: Pollutant concentrations indoors and outdoors from filtered datasets with the corresponding $p$-values from $\mathrm{K}-\mathrm{W}$ test on $\mathrm{I} / \mathrm{O}$ ratios between categories.

Author Contributions: Conceptualization, S.L.M., J.D.A. , E.J.C., E.D.R., and P.M.S.; methodology, S.L.M., J.D.A., E.J.C., E.D.R., J.L.H., and P.M.S.; software, P.M.S.; validation, S.L.M. and J.L.H.; formal analysis, P.M.S. and S.L.M.; investigation, P.M.S., J.D.A., E.J.C., E.D.R., J.L.H. and K.E.B.; resources, S.L.M., J.D.A., E.J.C., E.D.R. and J.L.H.; data curation, P.M.S., K.E.B. and J.L.H.; writing—original draft preparation, P.M.S.; writing—review and editing, S.L.M., J.D.A., E.J.C., E.D.R., K.E.B. and J.L.H.; visualization, P.M.S.; supervision, S.L.M.; project administration, S.L.M.; funding acquisition, S.L.M.

Funding: This work was supported by the Environment Protection Agency (EPA-G2014-STAR-A1, Miller).

Acknowledgments: The authors would like to thank Xcel Energy, Boulder Housing Partners and CDPHE for their genuine support, all the participating households, the advisory board and the research assistants: Hanadi Salamah, Maia Lenz, Tess Bloom, Ryan Hourigan, Sarah Hong, Eduardo Soderberg, Mohamed Eltarkawe, Alex Mass, Olivia Cecil and Adam Hester. The authors are also thankful to the Hannigan Lab at CU Boulder for their genuine support, especially Evan Coffey, Drew Meyers and Ricardo Piedrahita, and John Volkens from Colorado State University for the help with instrumentation. In addition, the authors would like to thank SKC Inc., ALS Laboratories and Ogawa and Co., USA, Inc. for their valuable support in sample analysis.

Conflicts of Interest: The authors declare no conflict of interest. The funders had no role in the design of the study; in the collection, analyses, or interpretation of data; in the writing of the manuscript, or in the decision to publish the results.

\section{References}

1. Klepeis, N.E.; Nelson, W.C.; Ott, W.R.; Robinson, J.P.; Tsang, A.M.; Switzer, P.; Behar, J.V.; Hern, S.C.; Engelmann, W.H. The National Human Activity Pattern Survey (NHAPS): A resource for assessing exposure to environmental pollutants. J. Expo. Sci. Environ. Epidemiol. 2001, 11, 231-252. [CrossRef] [PubMed]

2. Jacob, D.J.; Winner, D.A. Effect of climate change on air quality. Atmos. Environ. 2009, 43, 51-63. [CrossRef]

3. Kinney, P.L. Climate Change, Air Quality, and Human Health. Am. J. Prev. Med. 2008, 35, 459-467. [CrossRef] [PubMed]

4. Melamed, M.L.; Schmale, J.; Von Schneidemesser, E. Sustainable policy-Key considerations for air quality and climate change. Curr. Opin. Environ. Sustain. 2016, 23, 85-91. [CrossRef]

5. Lathière, J.; Hauglustaine, D.A.; De Noblet-Ducoudré, N.; Krinner, G.; Folberth, G.A. Past and future changes in biogenic volatile organic compound emissions simulated with a global dynamic vegetation model. Geophys. Res. Lett. 2005, 32. [CrossRef]

6. Clements, N.; Keady, P.; Emerson, J.B.; Fierer, N.; Miller, S.L. Seasonal Variability of Airborne Particulate Matter and Bacterial Concentrations in Colorado Homes. Atmosphere 2018, 9, 133. [CrossRef]

7. Meng, Z. Chemical Coupling Between Atmospheric Ozone and Particulate Matter. Science 1997, 277, $116-119$. [CrossRef]

8. Volkamer, R.; Jiménez, J.L.; Martini, F.S.; Dzepina, K.; Zhang, Q.; Salcedo, D.; Molina, L.T.; Worsnop, D.R.; Molina, M.J. Secondary organic aerosol formation from anthropogenic air pollution: Rapid and higher than expected. Geophys. Res. Lett. 2006, 33. [CrossRef]

9. Zhang, R.; Wang, G.; Guo, S.; Zamora, M.L.; Ying, Q.; Lin, Y.; Wang, W.; Hu, M.; Wang, Y. Formation of Urban Fine Particulate Matter. Chem. Rev. 2015, 115, 3803-3855. [CrossRef]

10. Schoennagel, T.; Veblen, T.T.; Romme, W.H. The Interaction of Fire, Fuels, and Climate across Rocky Mountain Forests. BioScience 2004, 54, 661. [CrossRef] 
11. Westerling, A.L.; Hidalgo, H.G.; Cayan, D.R.; Swetnam, T.W. Warming and Earlier Spring Increase Western U.S. Forest Wildfire Activity. Science 2006, 313, 940-943. [CrossRef] [PubMed]

12. Hodzic, A.; Madronich, S.; Bohn, B.; Massie, S.; Menut, L.; Wiedinmyer, C. Wildfire particulate matter in Europe during summer 2003: Meso-scale modeling of smoke emissions, transport and radiative effects. Atmos. Chem. Phys. Discuss. 2007, 7, 4043-4064. [CrossRef]

13. Mcmeeking, G.R.; Kreidenweis, S.M.; Lunden, M.; Carrillo, J.; Carrico, C.M.; Lee, T.; Herckes, P.; Engling, G.; Day, D.E.; Hand, J.; et al. Smoke-impacted regional haze in California during the summer of 2002. Agric. For. Meteorol. 2006, 137, 25-42. [CrossRef]

14. Kaskaoutis, D.; Kharol, S.K.; Sifakis, N.; Nastos, P.; Sharma, A.R.; Badarinath, K.; Kambezidis, H.; Nastos, P. Satellite monitoring of the biomass-burning aerosols during the wildfires of August 2007 in Greece: Climate implications. Atmos. Environ. 2011, 45, 716-726. [CrossRef]

15. Martín, M.V.; Heald, C.L.; Ford, B.; Prenni, A.J.; Wiedinmyer, C. A decadal satellite analysis of the origins and impacts of smoke in Colorado. Atmos. Chem. Phys. Discuss. 2013, 13, 8233-8260. [CrossRef]

16. Liu, D.-L.; Nazaroff, W.W. Particle Penetration through Building Cracks. Aerosol Sci. Technol. 2003, 37, 565-573. [CrossRef]

17. Liu, D.-L.; Nazaroff, W.W. Modeling pollutant penetration across building envelopes. Atmos. Environ. 2001, 35, 4451-4462. [CrossRef]

18. Long, C.M.; Suh, H.H.; Catalano, P.J.; Koutrakis, P. Using Time- and Size-Resolved Particulate Data To Quantify Indoor Penetration and Deposition Behavior. Environ. Sci. Technol. 2001, 35, 2089-2099. [CrossRef]

19. Henderson, D.E.; Milford, J.B.; Miller, S.L. Prescribed burns and wildfires in Colorado: Impacts of mitigation measures on indoor air particulate matter. J. Air Waste Manag. Assoc. 2005, 55, 1516-1526. [CrossRef]

20. Wang, F.; Meng, D.; Li, X.; Tan, J. Indoor-outdoor relationships of $\mathrm{PM}_{2.5}$ in four residential dwellings in winter in the Yangtze River Delta, China. Environ. Pollut. 2016, 215, 280-289. [CrossRef]

21. Alman, B.L.; Pfister, G.; Hao, H.; Stowell, J.; Hu, X.; Liu, Y.; Strickland, M.J. The association of wildfire smoke with respiratory and cardiovascular emergency department visits in Colorado in 2012: A case crossover study. Environ. Health 2016, 15, 4043. [CrossRef]

22. Liu, J.C.; Pereira, G.; Uhl, S.A.; Bravo, M.A.; Bell, M.L. A systematic review of the physical health impacts from non-occupational exposure to wildfire smoke. Environ. Res. 2015, 136, 120-132. [CrossRef]

23. Johnston, F.H.; Henderson, S.B.; Chen, Y.; Randerson, J.T.; Marlier, M.; DeFries, R.S.; Kinney, P.; Bowman, D.M.J.S.; Brauer, M. Estimated Global Mortality Attributable to Smoke from Landscape Fires. Environ. Health Perspect. 2012, 120, 695-701. [CrossRef]

24. Barn, P.; Larson, T.; Noullett, M.; Kennedy, S.; Copes, R.; Brauer, M. Infiltration of forest fire and residential wood smoke: An evaluation of air cleaner effectiveness. J. Expo. Sci. Environ. Epidemiol. 2008, 18, 503. [CrossRef]

25. Fisk, W.J.; Chan, W.R. Health benefits and costs of filtration interventions that reduce indoor exposure to PM2.5 during wildfires. Indoor Air 2017, 27, 191-204. [CrossRef]

26. Barn, P.K.; Elliott, C.T.; Allen, R.W.; Kosatsky, T.; Rideout, K.; Henderson, S.B. Portable air cleaners should be at the forefront of the public health response to landscape fire smoke. Environ. Health 2016, 15, 685. [CrossRef]

27. Baccarelli, A.; Martinelli, I.; Pegoraro, V.; Melly, S.; Grillo, P.; Zanobetti, A.; Hou, L.; Bertazzi, P.; Mannucci, P.; Schwartz, J. Living Near Major Traffic Roads and Risk of Deep Vein Thrombosis. Circulation 2009, 119, 3118-3124. [CrossRef]

28. Hoek, G.; Brunekreef, B.; Goldbohm, S.; Fischer, P.; Brandt, P.A.V.D. Association between mortality and indicators of traffic-related air pollution in the Netherlands: A cohort study. Lancet 2002, 360, 1203-1209. [CrossRef]

29. Hitchins, J.; Morawska, L.; Wolff, R.; Gilbert, D. Concentrations of submicrometre particles from vehicle emissions near a major road. Atmos. Environ. 2000, 34, 51-59. [CrossRef]

30. Briggs, D.J.; De Hoogh, C.; Gulliver, J.; Wills, J.; Elliott, P.; Kingham, S.; Smallbone, K. A regression-based method for mapping traffic-related air pollution: Application and testing in four contrasting urban environments. Sci. Total Environ. 2000, 253, 151-167. [CrossRef]

31. Carlton, E.J.; Barton, K.; Shrestha, P.M.; Humphrey, J.; Newman, L.S.; Adgate, J.L.; Root, E.; Miller, S. Relationships between home ventilation rates and respiratory health in the Colorado Home Energy Efficiency and Respiratory Health (CHEER) study. Environ. Res. 2019, 169, 297-307. [CrossRef] 
32. Haines, A.; Kovats, R.; Campbell-Lendrum, D.; Corvalan, C. Climate change and human health: Impacts, vulnerability and public health. Public Health 2006, 120, 585-596. [CrossRef]

33. O'Neill, M.S.; Jerrett, M.; Kawachi, I.; Levy, J.I.; Cohen, A.J.; Gouveia, N.; Wilkinson, P.; Fletcher, T.; Cifuentes, L.; Schwartz, J. Health, wealth, and air pollution: Advancing theory and methods. Environ. Health Perspect. 2003, 111, 1861-1870. [CrossRef]

34. Sexton, K.; Gong, H., Jr.; Bailar, J.C.; Ford, J.G.; Gold, D.R.; Lambert, W.E.; Utell, M.J. Air Pollution Health Risks: Do Class and Race Matter? Toxicol. Ind. Health 1993, 9, 843-878. [CrossRef]

35. Houston, D.; Wu, J.; Ong, P.; Winer, A. Structural Disparities of Urban Traffic in Southern California: Implications for Vehicle-Related Air Pollution Exposure in Minority and High-Poverty Neighborhoods. J. Urban Aff. 2004, 26, 565-592. [CrossRef]

36. Maantay, J. Asthma and air pollution in the Bronx: Methodological and data considerations in using GIS for environmental justice and health research. Health Place 2007, 13, 32-56. [CrossRef]

37. Adamkiewicz, G.; Zota, A.R.; Fabian, M.P.; Chahine, T.; Julien, R.; Spengler, J.D.; Levy, J.I. Moving Environmental Justice Indoors: Understanding Structural Influences on Residential Exposure Patterns in Low-Income Communities. AJPH 2011, 101, S238-S245. [CrossRef]

38. Boulder Housing Partners. Available online: https://boulderhousing.org/ (accessed on 10 July 2019).

39. Legal Information Institute. 40 CFR Appendix E to Part 58-Probe and Monitoring Path Siting Criteria for Ambient Air Quality Monitoring, LII. Available online: https://www.law.cornell.edu/cfr/text/40/appendix-E_ to_part_58 (accessed on 13 September 2019).

40. Hagler, G.S. Post-processing Method to Reduce Noise while Preserving High Time Resolution in Aethalometer Real-time Black Carbon Data. Aerosol Air Qual. Res. 2011, 11, 539-546. [CrossRef]

41. Pod Technology. Hannigan Air Quality and Technology Research Lab. University of Colorado Boulder. Available online: https://www.colorado.edu//lab/hannigan/pod-technology (accessed on 15 July 2019).

42. Arduino-Home. Available online: https://www.arduino.cc/ (accessed on 15 July 2019).

43. Piedrahita, R.; Xiang, Y.; Masson, N.; Ortega, J.; Collier, A.; Jiang, Y.; Li, K.; Dick, R.P.; Lv, Q.; Hannigan, M.; et al. The next generation of low-cost personal air quality sensors for quantitative exposure monitoring. Atmos. Meas. Tech. 2014, 7, 3325-3336. [CrossRef]

44. CDPHE—Colorado.gov/AirQuality. Available online: https://www.colorado.gov/airquality/site_description. aspx (accessed on 15 July 2019).

45. Cao, J.J.; Lee, S.-C.; Chow, J.C.; Cheng, Y.; Ho, K.F.; Fung, K.; Liu, S.X.; Watson, J.G. Indoor/outdoor relationships for PM2.5 and associated carbonaceous pollutants at residential homes in Hong Kong-Case study. Indoor Air 2005, 15, 197-204. [CrossRef]

46. Allen, R.; Larson, T.; Sheppard, L.; Wallace, L.; Liu, L.-J.S. Use of real-time light scattering data to estimate the contribution of infiltrated and indoor-generated particles to indoor air. Environ. Sci. Technol. 2003, 37, 3484-3492. [CrossRef]

47. Ramachandran, G.; Adgate, J.L.; Hill, N.; Sexton, K.; Pratt, G.C.; Bock, D. Comparison of Short-Term Variations (15-Minute Averages) in Outdoor and Indoor $\mathrm{PM}_{2.5}$ Concentrations. J. Air Waste Manag. Assoc. 2000, 50, 1157-1166. [CrossRef]

48. Garrett, M.H.; Hooper, M.A.; Hooper, B.M.; Abramson, M.J. Respiratory Symptoms in Children and Indoor Exposure to Nitrogen Dioxide and Gas Stoves. Am. J. Respir. Crit. Care Med. 1998, 158, 891-895. [CrossRef]

49. Dockery, D.W.; Spengler, J.D.; Reed, M.P.; Ware, J. Relationships among personal, indoor and outdoor $\mathrm{NO}_{2}$ measurements. Environ. Int. 1981, 5, 101-107. [CrossRef]

50. Ng, T.P.; Hui, K.P.; Tan, W.C. Respiratory symptoms and lung function effects of domestic exposure to tobacco smoke and cooking by gas in non-smoking women in Singapore. J. Epidemiol. Community Health 1993, 47, 454-458. [CrossRef]

51. NOAA's Office of Satellite and Product Operations. Available online: https://www.ospo.noaa.gov/Products/ land/hms.html (accessed on 16 July 2019).

52. Duncan, B.N.; Prados, A.I.; Lamsal, L.N.; Liu, Y.; Streets, D.G.; Gupta, P.; Hilsenrath, E.; Kahn, R.A.; Nielsen, J.E.; Beyersdorf, A.J.; et al. Satellite data of atmospheric pollution for U.S. air quality applications: Examples of applications, summary of data end-user resources, answers to FAQs, and common mistakes to avoid. Atmos. Environ. 2014, 94, 647-662. [CrossRef]

53. Data Catalog. Available online: http://dtdapps.coloradodot.info/otis/catalog (accessed on 16 July 2019). 
54. Carlsen, H.K.; Modig, L.; Levinsson, A.; Kim, J.-L.; Torén, K.; Nyberg, F.; Olin, A.-C. Exposure to traffic and lung function in adults: A general population cohort study. BMJ Open 2015, 5, e007624. [CrossRef]

55. Rose, N.; Cowie, C.; Gillett, R.; Marks, G.B. Weighted road density: A simple way of assigning traffic-related air pollution exposure. Atmos. Environ. 2009, 43, 5009-5014. [CrossRef]

56. Schikowski, T.; Sugiri, D.; Ranft, U.; Gehring, U.; Heinrich, J.; Wichmann, H.-E.; Krämer, U. Long-term air pollution exposure and living close to busy roads are associated with COPD in women. Respir. Res. 2005, 6, 152. [CrossRef]

57. Bowatte, G.; Erbas, B.; Lodge, C.J.; Knibbs, L.D.; Gurrin, L.C.; Marks, G.B.; Thomas, P.S.; Johns, D.P.; Giles, G.G.; Hui, J.; et al. Traffic-related air pollution exposure over a 5-year period is associated with increased risk of asthma and poor lung function in middle age. Eur. Respir. J. 2017, 50, 1602357. [CrossRef]

58. WHO Regional Office Europe. Health Effects of Transport-related Air Pollution. Available online: http://www.euro.who.int/_data/assets/pdf_file/0006/74715/E86650.pdf (accessed on 13 September 2019).

59. Dutton, S.J.; Schauer, J.J.; Vedal, S.; Hannigan, M.P. PM2.5 Characterization for Time Series Studies: Pointwise Uncertainty Estimation and Bulk Speciation Methods Applied in Denver. Atmos. Environ. 2009, 43, 1136-1146. [CrossRef]

60. Viana, M.; Díez, S.; Reche, C. Indoor and outdoor sources and infiltration processes of PM1 and black carbon in an urban environment. Atmos. Environ. 2011, 45, 6359-6367. [CrossRef]

61. Kaur, S.; Nieuwenhuijsen, M.; Colvile, R. Fine particulate matter and carbon monoxide exposure concentrations in urban street transport microenvironments. Atmos. Environ. 2007, 41, 4781-4810. [CrossRef]

62. Wang, Z.; Lu, Q.-C.; He, H.-D.; Wang, D.; Gao, Y.; Peng, Z.-R. Investigation of the spatiotemporal variation and influencing factors on fine particulate matter and carbon monoxide concentrations near a road intersection. Front. Earth Sci. 2017, 11, 63-75. [CrossRef]

63. Wang, J.; Chan, T.L.; Ning, Z.; Leung, C.W.; Cheung, C.S.; Hung, W.-T. Roadside measurement and prediction of $\mathrm{CO}$ and $\mathrm{PM}_{2.5}$ dispersion from on-road vehicles in Hong Kong. Transp. Res. Part D Transp. Environ. 2006, 11, 242-249. [CrossRef]

64. Clements, A.L.; Jia, Y.; DenBleyker, A.; McDonald-Buller, E.; Fraser, M.P.; Allen, D.T.; Collins, D.R.; Michel, E.; Pudota, J.; Sullivan, D.; et al. Air pollutant concentrations near three Texas roadways, part II: Chemical characterization and transformation of pollutants. Atmos. Environ. 2009, 43, 4523-4534. [CrossRef]

65. Luhar, A.K.; Patil, R.S. A General Finite Line Source Model for vehicular pollution prediction. Atmos. Environ. 1989, 23, 555-562. [CrossRef]

66. Roorda-Knape, M.C.; Janssen, N.A.; De Hartog, J.J.; Van Vliet, P.H.; Harssema, H.; Brunekreef, B. Air pollution from traffic in city districts near major motorways. Atmos. Environ. 1998, 32, 1921-1930. [CrossRef]

67. Weijers, E. Variability of particulate matter concentrations along roads and motorways determined by a moving measurement unit. Atmos. Environ. 2004, 38, 2993-3002. [CrossRef]

68. Townsend, C.L.; Maynard, R.L. Effects on health of prolonged exposure to low concentrations of carbon monoxide. Occup. Environ. Med. 2002, 59, 708-711. [CrossRef]

69. Levy, R.J. Carbon Monoxide Pollution and Neurodevelopment: A Public Health Concern. Neurotoxicol. Teratol. 2015, 49, 31-40. [CrossRef]

70. Whincup, P.; Papacosta, O.; Lennon, L.; Haines, A. Carboxyhaemoglobin levels and their determinants in older British men. BMC Public Health 2006, 6, 189. [CrossRef]

71. Ultrafine and Fine Particulate Matter Inside and Outside of Mechanically Ventilated Buildings. Available online: https://www.mdpi.com/1660-4601/14/2/128 (accessed on 25 July 2019).

72. Gilbert, N.L.; Woodhouse, S.; Stieb, D.M.; Brook, J.R. Ambient nitrogen dioxide and distance from a major highway. Sci. Total Environ. 2003, 312, 43-46. [CrossRef]

73. Relwani, S.M.; Moschandreas, D.J.; Billick, I.H. Effects of Operational Factors on Pollutant Emission Rates from Residential Gas Appliances. J. Air Pollut. Control Assoc. 1986, 36, 1233-1237. [CrossRef]

74. Lee, K.; Levy, J.I.; Yanagisawa, Y.; Spengler, J.D.; Billick, I.H. The Boston Residential Nitrogen Dioxide Characterization Study: Classification and Prediction of Indoor $\mathrm{NO}_{2}$ Exposure. J. Air Waste Manag. Assoc. 1998, 48, 736-742. [CrossRef]

75. Zhu, Y.; Hinds, W.C.; Kim, S.; Sioutas, C. Concentration and Size Distribution of Ultrafine Particles near a Major Highway. J. Air Waste Manag. Assoc. 2002, 52, 1032-1042. [CrossRef] 
76. Zhao, L.; Chen, C.; Wang, P.; Chen, Z.; Cao, S.-J.; Wang, Q.; Xie, G.; Wan, Y.; Wang, Y.; Lu, B. Influence of atmospheric fine particulate matter $\left(\mathrm{PM}_{2.5}\right)$ pollution on indoor environment during winter in Beijing. Build. Environ. 2015, 87, 283-291. [CrossRef]

77. Shi, S.; Zhao, B. Occupants' interactions with windows in 8 residential apartments in Beijing and Nanjing, China. Build. Simul. 2016, 9, 221-231. [CrossRef]

78. Liu, C.; Yang, J.; Ji, S.; Lu, Y.; Wu, P.; Chen, C.; Wu, B. Influence of natural ventilation rate on indoor $\mathrm{PM}_{2.5}$ deposition. Build. Environ. 2018, 144, 357-364. [CrossRef]

79. Abdel-Salam, M.M.M. Investigation of $\mathrm{PM}_{2.5}$ and carbon dioxide levels in urban homes. J. Air Waste Manag. Assoc. 2015, 65, 930-936. [CrossRef]

80. Tong, Z.; Chen, Y.; Malkawi, A.; Adamkiewicz, G.; Spengler, J.D. Quantifying the impact of traffic-related air pollution on the indoor air quality of a naturally ventilated building. Environ. Int. 2016, 89, 138-146. [CrossRef]

(c)

(C) 2019 by the authors. Licensee MDPI, Basel, Switzerland. This article is an open access article distributed under the terms and conditions of the Creative Commons Attribution (CC BY) license (http://creativecommons.org/licenses/by/4.0/). 